NBER WORKING PAPER SERIES

\title{
PARENTAL MONITORING AND CHILDREN'S INTERNET USE: THE ROLE OF INFORMATION, CONTROL, AND CUES
}

\author{
Francisco Gallego \\ Ofer Malamud \\ Cristian Pop-Eleches \\ Working Paper 23982 \\ http://www.nber.org/papers/w23982 \\ NATIONAL BUREAU OF ECONOMIC RESEARCH \\ 1050 Massachusetts Avenue \\ Cambridge, MA 02138 \\ October 2017, Revised August 2018
}

We would like thank Ramon Rodriguez and his staff at the Ministry of Education for providing the data and technical assistance necessary to conduct this study. We are especially grateful to Jaime Bellolio who collaborated with us on an evaluation of the "Yo Elijo mi PC" program that is the setting of the present study. Cristian Larroulet, Jose Ignacio Cuesta, Antonia Asenjo, Magdalena Bennet, Ana Mendoza, Dario Romero, Sebastian Otero, and Alejandro Saenz provided excellent research assistance. We would like to thank Paloma Acevedo, Felipe BarreraOsorio, Peter Bergman, Samuel Berlinski, Marianne Bertrand, Lucas Coffman, Stefano Dellavigna, Jeanne Lafortune, Claudia Martínez, Philip Oreopoulos, as well as seminar participants at Columbia Teacher's College, IFPRI, the Inter-American Development Bank, NBER Children Meetings, Northwestern University, Princeton University, PUC-Chile, and the University of Houston for comments and suggestions. We would like to thank FONDECYT (Project 1141111), J-PAL, the Columbia- Chile fund, and the Population Research Center, grant \# R24 HD051152-05 from the National Institute of Child Health and Human Development for financial support. All errors are our own. The views expressed herein are those of the authors and do not necessarily reflect the views of the National Bureau of Economic Research.

NBER working papers are circulated for discussion and comment purposes. They have not been peer-reviewed or been subject to the review by the NBER Board of Directors that accompanies official NBER publications.

(C) 2017 by Francisco Gallego, Ofer Malamud, and Cristian Pop-Eleches. All rights reserved. Short sections of text, not to exceed two paragraphs, may be quoted without explicit permission provided that full credit, including $(\odot$ notice, is given to the source. 
Parental Monitoring and Children's Internet Use: The Role of Information, Control, and Cues Francisco Gallego, Ofer Malamud, and Cristian Pop-Eleches

NBER Working Paper No. 23982

October 2017, Revised August 2018

JEL No. D82,I15,J12,J13

\section{ABSTRACT}

This paper explores how parental information and control can influence children's internet use in Chile. We designed and implemented a set of randomized interventions whereby approximately 7700 parents were sent weekly SMSs messages with (i) specific information about their children's internet use, and/or (ii) encouragement and assistance with the installation of parental control software. We separate the informational content from the cue associated with SMS messages and vary the strength of the cues by randomly assigning whether parents received messages in a predictable or unpredictable fashion. Our analysis yields three main findings. First, we find that messages providing parents with specific information affects parental behavior and reduces children's internet use by 6-10 percent. Second, we do not find significant impacts from helping parents directly control their children's internet access with parental control software. Third, the strength of the cue associated with receiving a message has a significant impact on internet use.

Francisco Gallego

Instituto de Economía

Pontificia Universidad Catolica de Chile

Av. Vicuna Mackenna 4860

Macul, Santiago

Chile

and EH Clio Lab

fgallego@puc.cl
Cristian Pop-Eleches

The School of International and Public Affairs

Columbia University

1401A International Affairs Building, MC 3308

420 West 118th Street

New York, NY 10027

and NBER

cp2124@columbia.edu

Ofer Malamud

School of Education and Social Policy

Northwestern University

Annenberg Hall

2120 Campus Drive

Evanston, IL 60208

and NBER

ofer.malamud@northwestern.edu 


\section{Introduction}

Economists have long been interested in how parents can influence their children's actions. ${ }^{1}$ However, in many situations, parents are unable to monitor their children because they lack information and cannot observe their children's actions. ${ }^{2}$ Even with perfect information, parents may not be able to affect their children's actions if they are unwilling to make negative transfers that impose large costs on the child (Weinberg, 2001; Berry, 2015). As a result, parents may wish for the possibility of controlling their children's actions directly. The first motivation of this paper is to explore the effect of providing parents with additional information and direct controls in the context of home computers and internet use. To this end, we designed and implemented a set of randomized interventions whereby we sent parents weekly SMS messages containing specific information about their children's recent internet use and/or encouragement and assistance with installing parental control software. ${ }^{3}$

The impact of providing parents with additional information or tools to directly control their children's actions may also depend on the cues associated with SMS messages. ${ }^{4}$ Thus, a second motivation of this paper is to better understand the role of cues in messages more generally. To this end, we also designed our interventions to separate the informational content from the cue associated with the SMS messages. In addition, we attempted to vary the strength or salience of the cues by randomly assigning whether parents received messages in a predictable or unpredictable fashion.

\footnotetext{
${ }^{1}$ For example, Becker $(1974,1981)$ introduced the "Rotten Kid Theorem" to show that, under certain assumptions, parents can determine their children's actions indirectly through ex-post transfers. 2 Relatedly, Bergstrom (1989) shows the Rotten Kid theorem does not hold in the presence of asymmetric information. Bursztyn and Coffman (2012) provide evidence for such asymmetric information in Brazil. ${ }^{3}$ A number of recent papers study the effect of sending SMS messages to parents with information from schools (Bergman, 2016; Bergman and Chan, 2017; Berlinski et al., 2017; Cunha, et al. 2017). Castleman and Page (2017) text parents about preparing their children for enrollment in college. Dizon-Ross (2018) and de Walque and Valente (2018) examine the in-person provision of information to parents. 4 Taubinsky (2014) considers cues in a model of inattentive choice. Bordalo, Gennaioli, and Schleifer (2017) present a theory in which cues that surprise relative to previous norms affect choice.
} 
This is inspired by research in neuroscience suggesting that human responses may be related to the predictability or novelty of the stimuli (Parkin, 1997; Berns et al., 2001; Fenker et al., 2008). It is also closely related to research in psychology on how different schedules of reinforcement affect behavior (Ferster and Skinner, 1957).

Exploring the role of parents when navigating home technology is instructive because the informational frictions are likely to be pronounced and implementing direct controls can be difficult; children are often quicker to adapt to new technologies and parents may encounter challenges in understanding how children use technology. Previous research has shown that access to home computers and internet have negative or null effects on academic achievement (Malamud and Pop-Eleches, 2011; Fairlie and Robinson, 2013; Beuermann, et al. 2015; Malamud et al. 2018; Vigdor, Ladd, and Martinez 2014). A recent study that exploits exogenous variation of internet penetration in Chile finds negative impacts of internet use on standardized test scores, especially for low-income families (Gonzalez, 2017). Given that computers represent such a versatile technology, the potential risks and benefits of computer use are likely to depend on parental involvement. Indeed, Malamud and Pop-Eleches (2011) found that parental rules for homework and computer use attenuated the negative effects of computer ownership, suggesting that parental supervision may be an important mediating factor.

We focus on a sample of children in $7^{\text {th }}$ and $8^{\text {th }}$ grade who received free computers and 12 months of free internet through Chile's "Yo Elijo mi PC" (YEMPC) program in 2013. We have data on the intensity of internet use at the daily level from the internet service provider (ISP) which served all of the computers provided to the children in our sample. According to this data, children used approximately $174 \mathrm{MB}$ of internet content daily, which translates to about 3 hours of internet use per day. This is 
similar to recent estimates from a 2015 PISA survey showing that children in Chile spent 195-230 minutes online per day, the highest rate among all the OECD countries surveyed (OECD, 2017). To put this in context, the American Academy of Pediatrics (AAP) recommends no more than 2 hours of screen time for children (AAP, 2016). Furthermore, over 75 percent of the parents in our baseline survey expressed the view that their children used too much internet or the wish to better control their children's internet use.

Our unique data enabled us to introduce a treatment that provided parents with information about their children's internet use. For this "ISP information" treatment, we sent parents weekly SMS messages providing specific information from the ISP about the intensity of internet use, in terms of MBs uploaded/downloaded, over the previous week. For the "parental control" treatment, we sent parents weekly SMSs offering assistance with the installation of Windows 8 (W8) parental control software. We also incorporated a treatment arm that included both ISP information and assistance with W8 parental controls to test for possible interactions between these treatments.

To disentangle the informational content and the offer of assistance from the cue associated with SMS messages, we compare these treatments to a control group in which parents received generic SMSs reminding them that children should make good use of their computers, a message that was included in every treatment. Furthermore, we attempted to vary the strength or salience of the cue within each of our treatment arms by randomly assigning parents to either receive the SMSs on the same day of the week (the "fixed" subgroups) or a on random day of the week (the "random" subgroups). All of these interventions lasted for 14 weeks.

We have three main sets of results. First, we find that households in which parents received ISP information about internet use had 6 to 10 percent lower intensity 
of internet use during the treatment period relative to households in the control group. These effects persist in the weeks and months after treatment ended. They do not reflect declines in parents' own internet use. This suggests that our temporary intervention providing information on internet use may have altered the permanent intra-household equilibrium. Indeed, some parents who received information reported that they were more likely to punish their children and some reported having calm discussions with their children about internet use. There is even some evidence that parenting styles become less permissive. Furthermore, we find that our informational interventions may substitute for the presence of a parent at home but are complementary to parents' capacity to be involved in their children's lives.

We also show that there are statistically significant reductions of internet use precisely on the days immediately after receiving the ISP information, and that this effect is more relevant in the early weeks of the experiment. The decline in internet use is largest for parents who didn't think their children used too much internet at baseline but whose children had high levels of internet use. Similarly, we find stronger impacts of providing ISP information in the upper quintiles of the distribution of internet use. Moreover, it is those SMS messages conveying that children used more internet than the reference group in a specific week, which produce a much larger decline in internet use. These findings confirm that it is specific information provided to parents about their children's internet use that leads to significant reductions of internet use.

Second, we do not find significant impacts from helping parents directly control their children's internet access. In particular, we do not find a difference in internet use between parents who were encouraged and provided assistance to install parental control software as compared with those in the control group who only received a generic message. Take-up of this intervention was only 15 percent when measured in 
terms of parents who actually responded to our messages. However, for those taking up the intervention, we do not find changes in internet use even on the days immediately after installing the parental control settings. We believe these findings reflect the considerable obstacles faced by low-income parents in implementing technological solutions for monitoring and supervising their children.

Third, we have several results that help us open the "black box" of how messages that contain information can affect behavior. As mentioned above, by sending messages that vary the amount of information, we show that a message's informational content reduces internet use. Our analysis also yields two additional findings that suggest the importance of cues. When we experimentally varied the strength or salience of the cue, we find that households who received SMSs on a random schedule experienced significantly greater reductions in internet use than those on fixed schedules, an effect similar in magnitude to the main effect associated with receiving the ISP information. Furthermore, we find that even the SMS messages sent to the control group had shortterm impacts on internet use in the first weeks of the experiment, perhaps due to the novelty of the message.

Our paper makes several contributions: First, we identify real-time impacts of the provision of information on internet use, an important dimension of children's behavior at home that is often imperfectly observed to parents. Second, we use experimental variation to isolate the causal effect of providing parents with specific information and helping parents exercise direct control over their children's behavior. Third, we isolate the impact of providing parents with specific information from the effect of a cue associated with receiving a message. Such cues are likely to be an important part of any attempt to provide parents (or other economic actors) with information. Fourth, we further explore the role of these cues by introducing 
experimental variation in when parents received SMS messages. Thus, this study provides a unique opportunity to explore factors that affect parental monitoring and to better understand how and why messages containing information affect behavior.

The paper is organized as follows: Section 2 provides some background on the Yo Elijo mi PC program and the experimental design. Section 3 describes the data, the empirical strategy, and examines take-up. Section 4 presents the main findings. Section 5 explores the important role of parents. Section 6 presents further results. Finally, Section 7 concludes.

\section{Background}

\subsection{The Yo Elijo mi PC (YEMPC) program}

We designed and implemented our experiment for the 2013 cohort of the YEMPC program. YEMPC is a Chilean government program that provides computers to $7^{\text {th }}$ graders with high academic achievement from disadvantaged households. Students are eligible for the program if they have attained a sufficiently high grade point average (GPA) in 4th, $5^{\text {th }}$, and the first semester of 6th grade and if their household scored below a certain level on a measure of poverty used to determine eligibility for social programs called the Ficha de Protección Social (FPS).

The timeline of YEMPC for each round is as follows: Eligible students are identified based on their FPS and GPA scores in September-October of the year prior to receipt of the computer. Every student who meets the FPS and GPA requirements is eligible to receive a computer; there is no application process. Students select a computer in November-December. A number of options are available each year, although all computers were equipped with Windows 8 and Microsoft Office. Computers are distributed to students during the months of April and May. The 
computers are given in schools, at a ceremony organized by the municipality in which the student is enrolled. Beginning with the 2011 cohort, students with some types of computers also received 12 months of free internet service through a private Internet Service Provider (ISP).

Our experiment centers on students who entered $7^{\text {th }}$ grade in 2013 and were selected to the program in November 2012. Figure 1 presents the timeline associated with the 2013 cohort of the YEMPC. We focus on the 32,270 beneficiaries of this cohort who received free internet access with their computers starting in mid-2013 (out of a total of 52,122 beneficiaries). We called parents by phone using contact information from the program's administrative records, asking them to participate in the study and complete a telephone baseline survey. Our final analysis sample consists of 7,707 parents with a valid cell phone (which we require to implement our SMS interventions) and who consented to participate in the experiment. ${ }^{5}$

Prior to receiving computers through the YEMPC program, $40 \%$ of beneficiaries had a PC at home, 23\% had internet access at home, and 6\% had a cell phone with internet access. ${ }^{6}$ Furthermore, the median student reported only having "access to internet some times in the week". This contrasts with an average of three hours of internet use per day at the baseline of our experiment. Did the increase in internet use benefit children? As mentioned earlier, previous research on the effect of internet use in Chile and in the United States indicates negative effects on academic achievement. Moreover, based on data from our baseline survey, over 75 percent of the parents expressed the view that their children used too much internet or the wish to better control their children's

\footnotetext{
${ }^{5}$ Appendix Table 1 compares the students in our analysis sample with a broader sample of those who received a computer with free internet through the "Yo Elijo Mi PC" program. We do not observe large differences between the analysis sample and the broader sample.

${ }^{6}$ This is based on surveys completed by students when selecting a computer from the YEMPC program.
} 
internet use. That said, even if internet use is not detrimental for children's outcomes, the findings in our paper are still important for understanding how information and cues affect behavior.

\subsection{Experimental Design}

The intervention consists of delivering weekly text messages to the 7,707 parents in our experimental sample. The SMSs differed in terms of content and the day of the week in which they were delivered. In terms of content, we had three types of SMSs based on the following scripts:

- SMS-only: "We hope your child makes good use of the Yo Elijo Mi PC laptop that he/she won".

- ISP: "We hope your child makes good use of the Yo Elijo Mi PC laptop that he/she won. Your child downloaded XX MBs the week of the DD-MMM, \{"more than", or "similar to", or "less than"\} what a typical child downloaded: YY MBs." 7

- W8: "We hope your child makes good use of the Yo Elijo Mi PC laptop that he/she won. The Parental Control program of Windows 8 can help you supervise your child's computer use. Call us at XXX-XXXX for assistance."

Group T0 received the SMS-only message, group T1 received the ISP message, group T2 received the W8 message, and group T3 received both the ISP and W8 messages (in that order). For each group, half of the families received the treatments on a fixed day of the week (and we randomized the day on which they received the message) and half of the families received the messages on random days of each week. Table 1 shows how the 7,707 families were divided into the different experimental groups.

\footnotetext{
${ }^{7}$ We calculate weekly MBs downloaded by a "typical child" using a separate reference group of 1,929 children who received free internet through the YEMPC program.
} 
We used information from a baseline survey and administrative data on internet use to implement a stratified randomization with the following strata: (i) guardian's education (No High-School, High School, College), (ii) parent perception of whether the student stays too long in front of the computer (Yes or No), and (iii) total MBs downloaded in the pre-treatment period between September and December 15, 2013. The messages were sent weekly between $4 \mathrm{pm}$ and $5 \mathrm{pm}$ on different days of the week between December 23, 2013 and April 6, 2014. This period covers the summer vacation (from December, 232013 to March 6, 2014) and the school period (from March 7, 2014).

\section{Empirical Framework}

\subsection{Data}

The main source of data for our study is administrative data on internet use for each beneficiary collected by the ISP provider. This includes daily information on MBs downloaded and uploaded. We received this information for each beneficiary from September 22, 2014 to June, 17, 2015. Thus, we have information on internet use for the period before the SMS treatments started, for the period in which the SMSs were delivered, and for 12 weeks after the treatment was discontinued. In addition, we used information from the baseline survey to conduct the stratified randomization and to control for several baseline characteristics in our main specifications. These include student gender, guardian age, family composition, number of siblings, parents' education, parents' working conditions, and guardian's perceptions of internet and computer use. We have information for all the individuals included in the sample, as this was part of the enrollment process. 
Table 2 summarizes student and parental characteristics for our main experimental sample. The daily mean MBs used in the 3 months of the pre-treatment period was approximately $174 \mathrm{MB}$ which corresponds to 186 minutes of predicted internet use. Almost all of the children in our sample live with their mothers, and over sixty percent also live with their fathers. Moreover, about three-quarters have a sibling living with them while fifteen percent also live with a grandparent. Our sample of students is 43 percent female and have an average of 1.7 siblings. The average age of the guardian is 40 years old. Most guardians have some secondary education, with just 4 percent having some higher education, and the remainder with elementary education, which is not surprising given the target population of the YEMPC program.

During the treatment period, we were able to gather information about whether the SMSs sent were received on the cell phones of treated parents. This serves to measure the "technical" part of the take-up, as related to the actual delivery of the messages. We also collected data on the installation of W8 parental control setting through our call center. This measure captures the take-up of the W8 treatment directly from us, though parents could also install parental control software by other means.

Then, after the treatment ended, we applied a brief phone interview between April and early May 2014 to explore some potential mechanisms underlying our estimated impacts. We were able to contact 5,001 parents who consented to participate in this follow-up survey. This is equivalent to $57 \%$ of the original sample. The lower rate is mostly a consequence of the difficulty in reaching parents on the phone; the rejection rate of the survey was only about $14 \%$. The survey includes a series of questions about 
parent recollections of receiving SMSs, the usefulness of the SMSs, and the decision to install the parental control software, as well as parental behavior and parenting styles. ${ }^{8}$

Finally, in order to help with the interpretation of our results, we constructed a proxy for time use using information from students of the 2012 YEMPC cohort. For this earlier cohort, we have information on both MBs (downloaded and uploaded) and time of internet connection for a sample of 48,920 students for 125 days (from mid-April to early December, 2012). Using this information we estimated OLS regressions models with time of internet use as a non-linear functions (including interactions) of MB downloaded, MB uploaded, dummies for the day of the week, dummies for holidays, and dummies for discrete levels of use (four categories that reflect higher, high, normal, low use). We use the specification with the highest $\mathrm{R}^{2}(0.621)$ to impute time of internet use for our sample. We present these estimates to aid in the interpretation of our main results and use them as robustness checks.

Table 3 shows balance in the main demographic characteristics for our sample across each of our treatment arms, $\mathrm{T} 1, \mathrm{~T} 2$, and $\mathrm{T} 3$ relative to the control group $\mathrm{T} 0$. The F-test presented in the last column rejects balance at the $10 \%$ level for just one variable: whether the child lives with their mother. ${ }^{9}$ Still, the differences in averages for this variable across groups do not seem to be economically large. We control for this vector of covariates in some of our regression specifications and, not surprisingly given the balance across treatment arms, our coefficients remain largely unchanged.

\footnotetext{
${ }^{8}$ Appendix Table 1 compares baseline characteristics between the baseline and follow-up samples. ${ }_{9}^{9}$ Appendix Table 2 presents balance tests for the random/fixed schedule sub-treatments and Appendix Table 3 presents balance tests for the survey sample. We only observe two unbalanced variables for the random/fixed schedule comparisons (out of 20), and with small differences: the random-schedule households have slightly fewer parents with complete higher education (1 p.p.) and were present with a higher probability in the other category group for current employment status (1.p.p.).
} 


\subsection{Empirical Strategy}

We consider two alternative approaches for estimating the impact of our main interventions on internet use. First, we compare average internet use across households allocated to the different treatment groups. This allows us to identify the average effect on internet use over the entire treatment period, and beyond. Second, we analyze the effects of the actual receipt of the SMS messages using an event study framework in which we exploit within-event variation in internet use at the daily level. This enables us to better understand the mechanisms behind the changes in behavior.

For the first approach, we adopt the standard specification used to analyze randomized experiments by separately identifying the impacts of each treatment arm, $\mathrm{T} 1, \mathrm{~T} 2$, or $\mathrm{T} 3$ relative to our control group T0:

$$
Y_{i}=\beta^{\prime} X_{i}+\delta_{1} T 1_{i}+\delta_{2} T 2_{i}+\delta_{3} T 3_{i}+\varepsilon_{i}
$$

where $Y_{i}$ is a measure of internet use for household $i$. Our set of control variables $\left(X_{i}\right)$ includes strata fixed effects and internet use in the pre-treatment period; in some specification we also include demographic characteristics collected at baseline. The coefficient on $\mathrm{T} 1$ captures the effect of receiving ISP information with respect to the control group T0, the coefficient on T2 captures the effect of receiving information on how to install parental controls with respect to the control group, and T3 captures the effect of receiving information on both ISP and how to install parental controls. To the extent that not all of the SMSs sent are actually received, these coefficients will reflect intention-to-treat (ITT) parameters. These coefficients can be scaled up by the fraction of messages received, although as shown below, the vast majority of SMSs sent were actually received. 
To further improve precision, we also consider an alternative regression model that accounts for the fact that group T3 effectively receives both of the treatments provided to groups $\mathrm{T} 1$ and $\mathrm{T} 2$ :

$$
Y_{i}=\beta^{\prime} X_{i}+\delta_{1} \text { ISP_Information }_{i}+\delta_{2} \text { ParentalControls }_{i}+\epsilon_{i}
$$

where $Y_{i}$ and $X_{i}$ are defined as before, ISP_Information is $_{i}$ an indicator for households that are either in group T1 or T3, and ParentalControls $s_{i}$ is an indicator for households that are either in group T1 or T3. Thus, we simultaneously estimate the impact of parents receiving ISP information and assistance with W8 parental controls regardless of whether they are in $\mathrm{T} 1, \mathrm{~T} 2$, or $\mathrm{T} 3$. This specification assumes that there are no complementarities between the two separate SMS scripts. As shown below, we do not observe any significant effects for $\mathrm{T} 2$ relative to the control group and the estimated impacts for T3 are similar to those estimated for T1. Therefore, we believe that the assumption underlying this alternative model generally holds true.

For the second approach, we estimate the effect of each SMS "event" on internet use in the days immediately preceding and following the day on which the message was sent. We stack all the events for each sub-treatment and estimate the following model:

$$
\begin{gathered}
Y_{\text {ide }}=\sum_{d=-3}^{-2} \theta_{d} D_{d}+\sum_{t=0}^{3} \theta_{d} D_{d}+\sum_{d=-3}^{-2} \theta_{d}^{I S P} D_{d} * I S P_{i}+\sum_{t=0}^{3} \theta_{d}^{I S P} D_{d} * I S P_{i} \\
+\sum_{d=-3}^{-2} \theta_{d}^{P C} D_{d} * P C_{i}+\sum_{t=0}^{3} \theta_{d}^{P C} D_{d} * P C_{i}+\mu_{e}+e_{i d e}
\end{gathered}
$$

or, with abuse of notation (because we are not explicitly excluding $d=-1$ )

$$
Y_{i d e}=\sum_{d=-3}^{3} \theta_{d} D_{d}+\sum_{d=-3}^{3} \theta_{d}^{I S P} D_{d} * I S P_{i}+\sum_{d=-3}^{3} \theta_{d}^{P C} D_{d} * P C_{i}+\mu_{e}+\varepsilon_{i d e}
$$

where $Y$ and $i$ are defined as before, $d$ refers to the day, $e$ refers to the event, ISP is a dummy that takes a value of 1 for households in the ISP information group, $P C$ is a dummy that takes a value of 1 for households in the parental controls group, $D$ refers to 
day dummy variables, and $\mu_{\mathrm{e}}$ denote the event fixed effects. This approach allows us to estimate a vector of coefficients that capture differences in internet use with respect to day -1 (the day before actually receiving the treatment) for each treatment groups. For instance, $\theta-3$ measures the difference in internet use three days before receiving the message with respect to the day before the message was received for the control group, $\left(\theta_{-3}+\theta_{-3}\right.$ ISP $)$ is the same effect for households in the ISP information group, and $\left(\theta_{-3}+\theta_{-}\right.$ ${ }_{3}{ }^{\mathrm{PC}}$ ) for the parental control group.

We also estimate the impact of our sub-treatments in which we vary whether the SMSs are sent in a predictable or unpredictable fashion. To do this, we estimate the following regression model:

$$
Y_{i}=\beta^{\prime} X_{i}+\rho \text { Random }_{i}+\mu_{i}
$$

where $\operatorname{Random}_{i}$ equals 1 if the SMSs were sent on a random day of the week and 0 if the SMSs were sent on the same day of each week. The coefficient $\rho$ captures the impact of receiving the message on a random day relative to a fixed day of the week.

Finally, we consider a specification that allows for the interaction of our main treatments that provide ISP information or parental controls with our sub-treatments which vary whether the SMSs were sent in a predictable or unpredictable fashion:

$$
\begin{aligned}
Y_{i}=\beta^{\prime} X_{i}+\delta_{1} \text { ISP_Info }_{i}+\delta_{2} \text { ParentalControls }_{i}+\rho_{1} \text { Random }_{i} \\
\\
+\eta\left(\text { ISP_Info }_{i} * \text { Random }_{i}\right)+\theta\left(\text { ParentalControls }_{i} * \text { Random }_{i}\right)+\mu_{i}
\end{aligned}
$$

The coefficients $\eta$ and $\theta$ indicate whether providing information and parental controls are complements (or substitutes) with the strength or salience of the cue.

\subsection{Take-up}

We begin by showing the patterns of take-up using our administrative data in Table 4 . Columns (1) and (2) confirm that households were correctly targeted to receive SMSs 
with information about internet use from the ISP provider. From Panel A, those in groups T1 and T3 received approximately 82 percent of these SMSs whereas those in group T2 and the control group did not receive them. This is also apparent when using our alternative regression model in Panel B to estimate the combined impact of providing ISP Information from T1 and T3. Similarly, columns (3) and (4) confirm that households were correctly targeted to receive SMSs regarding the Windows 8 parental control software. Those in groups T2 and T3 received 83 percent and 81 percent of these SMSs while those in group T1 and the control group did not receive them at all.10 The imperfect compliance in the administrative data represents cases in which the SMS messages were not delivered due to technical issues (i.e. server problems, lack of reception, etc.). However, as shown in Appendix Table 4, the vast majority of parents received at least one message (98\% in the case of $\mathrm{T} 1$ and $\mathrm{T} 2$ and $97 \%$ in the case $\mathrm{T} 3$ ). Finally, columns (5) and (6) of Table 4 show that about 14 percent of households in treatment group T2 and 16 percent of households in group T3 received assistance from us with installing the W8 parental control software; as expected, these rates were zero in treatment group $\mathrm{T} 1$ and the control group. ${ }^{11}$

After treatment ended, we also asked parents about their recollections of receiving SMSs, the usefulness of the SMSs, and their decision to install parental control software. Column (1) of Panel A in Table 5 indicates no significant differences in whether parents recalled ever receiving an SMS across the different treatment arms T1, T2 and T3, relative to a base of 86 percent in the control group. This is not surprising

\footnotetext{
${ }^{10}$ Panel B does show a small but significant effect of the combined impact of ISP Information from T1 and T3 on the likelihood of receiving SMSs regarding W8 parental control software. This is a result of the small differences in take-up between $\mathrm{T} 2$ and $\mathrm{T} 3$.

${ }^{11}$ Again, Panel B shows a small but significant effect of the combined impact of ISP Information from T1 and T3 on the likelihood of installing the W8 parental control software as a result of the small differences in take-up between $\mathrm{T} 2$ and $\mathrm{T} 3$.
} 
given that all households were sent a weekly SMS (though Panel B does suggest that slightly fewer parents who received the Parental Control interventions report ever receiving an SMS). However, column (2) indicates that, among parents in group T2 who only received an SMS regarding W8 parental controls, significantly fewer remembered what the SMS actually said as compared to the control group. In contrast, among parents in groups T1 and T3 who received an SMS regarding the ISP internet use, significantly more remembered what the SMS actually said as compared to the control group. This differential rate of recall may also explain some of the differences in the impacts between the IPS and W8 interventions.

Columns (3)-(6) show whether, conditional on reporting the receipt of an SMS, parents found the SMSs useful. As expected, parents in groups T1 and T3 who received SMSs providing information about their children's internet use were significantly more likely to find these messages useful for being informed about internet use. While about 20 percent of parents in the control group discussed the SMSs with their kids, this fraction more than doubles for parents in groups that received information. Parents in groups T2 and T3 who received SMSs about the W8 parental controls were significantly more likely to find them useful for learning about tools that would be helpful to monitor use. We also find that, despite the fact that all treatment arms also contained a sentence reminding parents to ensure their children made good use of the computer, fewer households in treatment groups T1, T2, and T3 reported that their messages were useful for this purpose as compared to the control group which contained only this sentence. This present a first indication for the limited attention of parents; including additional content in the SMS may have led parents to pay less attention to the first part of the SMS. 
Column (7) indicates that parents in groups T2 and T3 who received information about the W8 parental controls software were more likely to install it. Yet there is also evidence that some parents in group T1 and the control group succeeded in installing parental control software despite not receiving any assistance from us. Furthermore, while the estimates are not significant, column (8) suggests that parents may have used the internet more themselves. The positive coefficients are consistent with the possibility that parents increased use in order to supervise and monitor their children. Overall, our administrative and survey data suggest that the interventions worked as intended and that the actual content of the SMSs did matter. Nevertheless, take-up associated with installing the Windows 8 (W8) parental control software was quite low.

\section{Main Results}

This section describes our main results on the role of information, parental controls, and cues for parental monitoring and supervision of children's internet use.

\subsection{Information}

We begin with a discussion of the aggregate impacts of providing parents with ISP information on the intensity of internet use. Across the different specifications in Panel A of Table 6, there is evidence that households in group T1 in which parents received the ISP information about internet use had lower intensity of internet use during the treatment period. The daily reduction of 11-16 megabytes used represents a 6-10 percent decrease relative to the control group. The impacts for households in group T3, in which parents were provided with both information about internet use and help installing parental controls, are negative but somewhat smaller in magnitude and less significant than those for T1. A broadly similar pattern is observed in Panel B where the 
increased precision yields a highly significant impact of providing ISP Information from T1 and T3 combined.

These results indicate that providing parents with specific information about their children's internet use leads to a significant reduction of 6-10 percent in contemporaneous internet use. This translates to a daily reduction of about 8 minutes of internet use in households that received the ISP information intervention (see Appendix Table 5 for estimates in terms of predicted minutes of use). We take this as evidence of a reduction in children's internet use because we did not observe declines in parents' report of their own use (in column 8 of Table 5).

For the most part, the impacts of our interventions are similar across weekdays and weekends. This may be because the patterns of internet use and parental monitoring do not vary between weekdays and weekends. Indeed, we do not see large differences in internet use for the control group between weekdays and weekends; average internet use is 169.4 and 167.6 for weekdays and weekends respectively. However, it is also possible that there are countervailing forces at play. For example, children's demand for internet may be higher during weekends but the ability of parents to monitor their children's internet use may also be correspondingly greater.

We do observe variation in treatment impacts for different levels of internet use using quantile regressions. Figure 2 plots the point estimates for the impact of providing ISP information for different quintiles of the distribution of outcomes (the underlying coefficients are in Appendix Table A6). The effects of providing information are concentrated in children above the median, and the absolute value of these estimates increases almost monotonically from -12 MBs for quintile 45 to -64 MBs for quintile 95. These results suggest that the effects of the informational intervention were 
concentrated among children with high levels of use, and who may have benefitted the most from a reduction in internet use.

We also explore the high-frequency dynamics of our interventions by implementing an event study analysis that exploits the timing of the messages within each week. ${ }^{12}$ The results are presented in Panel A of Figure 3 which plots coefficient estimates for the control group (SMS-only), the information treatment (ISP info) group, and the parental control group (PC). Day 0 marks the day on which the SMSs are received each week, although the messages were received in the afternoon so we may expect larger impacts on the following day (day 1). For ease of comparison, we normalize all of the coefficients to equal zero on the day prior to receipt of the SMS (day -1). These coefficients are also presented in Appendix Table 7 along with their standard errors.

We do not observe a trend for any of the groups in the days preceding receipt of the SMS (days -3 to -1). However, we do see significant differences emerge as the SMSs are received by the households. Internet use starts declining for the ISP Info group on day 0 , declines further on day 1 , and remains below the internet use in the days before the SMS is received. The plot for the control group does not follow the same pattern. While there is a small decrease on day 1 , this quickly reverts to the level of the days before the messages were sent. This confirms that the receipt of the SMS messages themselves leads to a discernible effect on internet use.

The impact associated with the actual content of the message received by the ISP-info group is shown in the two bottom panels of Figure 3. In particular, we split the sample between those receiving a message stating that internet use in the previous

\footnotetext{
12 This approach is similar to one taken by Alcott and Rogers (2014) in their paper examining the effect of providing information to electricity consumers.
} 
week was "above" the mean of the reference group and those receiving a message stating that internet use was the "same or below" the mean. The results indicate that the observed effects in the top panel of Figure 3 are driven by those SMS messages containing "bad news" for the parents. We do not see a similar pattern for the other two groups, which suggests that this is not explained by mean-reversion in internet use. ${ }^{13}$ This further confirms that the actual content of the message matters and not simply the receipt of the SMS messages.

To summarize, these results suggest that providing parents with information about their children's internet use helps to alleviate their lack of information. By having a control group that also receives an SMS message, we can isolate the impact of information from the cue associated with the message itself. Moreover, the evidence from our event study analysis showing that message content drives the impacts only serves to reinforce the fact that it is the information itself which generates the causal impact on internet use.

\subsection{Parental Controls}

Next we consider the impact of offering assistance with installing parental control software on the intensity of internet use. Looking at Panel A of Table 6, we see no significant effects for households in group T2 in which parents were provided with information about installing parental controls; if anything, the coefficients are slightly positive. There are also no significant effects in Panel B where we estimate the (combined) impact of offering parental control software from T2 and T3; the point

\footnotetext{
${ }^{13}$ We also verified that a similar pattern is observed when restricting to only the first SMS. Thus, when the first SMS received indicates that internet use is "above" average, there is a significant reduction in internet use in the days immediately after. Interestingly, when the first SMS indicates that internet use is "similar or below" average, there is actually an increase in internet use in the days immediately after.
} 
estimates are all clustered close to zero. Thus, the aggregate data suggests that offering parents with assistance to install parental control software is not an effective way of changing behavior. This is also in line with results from the event study analysis. In contrast to the patterns observed for the informational treatment, Figure 3 shows no discernable impact of parental control intervention on intensity of internet use in the days immediately following receipt of the SMS message. Finally, the quantile regressions in Figure 2 and Appendix Table A6 do not reveal any heterogeneous effects of parental controls by the level of internet use.

As a further exercise, we consider an alternative event-study analysis in which we estimate the short-term impact of actually installing W8 parental control software. Since we provided assistance with installing parental control software to families in treatment groups T2 and T3, we know the precise date on which each of the 564 parents who called received this assistance. These dates are staggered through January (after which no more calls were received), which allows us to estimate an event study that controls for seasonality, similar to those used in estimating the impact of receiving an SMS. The results of this analysis are shown in Figure 4 and Appendix Table 8 which indicate no significant short-term impacts in the days immediately after installation of the W8 parental control software. Given that the decision to install parental control software could be endogenous to internet use, these findings need to be interpreted with care. However, they are consistent with our previous results.

The absence of significant impacts from providing assistance for installing parental control software could indicate that parents already have access to other means of controlling their children's computer use. This may also explain the low rate of take-up for this intervention. Alternatively, the low rate of take-up could reflect the considerable obstacles faced by low-income parents in implementing technological 
solutions for monitoring and supervising their children. As noted previously, parents in this treatment arm were more likely to report learning about tools that can be helpful in monitoring their children. But perhaps such parents need more hands-on assistance to actually use parental control software on their children's computers. ${ }^{14}$ Moreover, installing and operating parental control software can impose substantial time costs which may lead to procrastination, status-quo bias, and other biases that arise with the demand for commitment devices (see Bryan et al., 2010 for a review).

\subsection{Cues}

As explained above, our interventions were designed to separate the informational content and the offer of assistance with parental control software from the cue associated with the SMS messages. This section presents additional evidence suggesting that the cues themselves also play an important role in affected parental behavior.

First, we use our event study framework to show that SMS messages sent to the control group had short-term impacts in the first weeks of the experiment. Figure 5 and Appendix Table 9 present the impacts from the event study for each treatment group during the first and second half of the treatment period. We discuss the implications of these patterns for the persistence of our main interventions in a subsequent section. However, it is notable that there is a negative and statistically significant decrease of about 10 MBs the day after SMS messages were received for the control group during the first half of the treatment period. This suggests that the salience of the message also matters since the SMS messages without specific information on internet use are likely to be more salient at the beginning of the experiment.

\footnotetext{
${ }^{14}$ We have examined which parental characteristics predict take-up of the W8 parental control software. The strongest predictors are the gender of the student (less likely to install for females) and the stated intention to install parental control software in the baseline survey.
} 
Second, we consider the effect of varying the strength of the cue associated with messages by sending them in either a predictable or unpredictable fashion. For each treatment arm, a random subset of households received SMSs on the same day of the week (this fixed day was randomly drawn for households) while the remainder of households received SMSs on a random day of the week. Table 7 examines the effect of receiving SMSs on a random versus a fixed schedule. Households who received SMSs on a random schedule had reductions of 10-15 MBs in daily internet use relative to households on fixed schedules. This is similar in magnitude to the main effect associated with receiving ISP information, and suggests that the strength of the cue associated to the message is as important as the message itself.

We believe these findings are consistent with research in neuroscience and psychology finding that unpredictable and novelty stimuli have larger impacts (e.g. Parkin, 1997; Berns et al., 2001; Fenker et al., 2008). They are also related to research in behavioral economics that emphasizes the role of inattention in the context of reminders (e.g., Karlan, et al. 2014, Taubinsky 2014, Ericsson, 2017). An alternative explanation for these patterns is that random schedules allow for more flexible responses by parents when receiving a message is not as convenient on some days (and the impact of repeated messages is non-linear). In this case, we would expect to find heterogeneous treatment effects by the day of the week in which the message was delivered. However, we do not find statistically significant differences across days.

\section{The Role of Parents}

Since our interventions were targeted at parents, it is important to understand how our main impacts are moderated by parental characteristics and mediated by parental 
behavior. This section uses information from both the baseline and endline survey to explore the role of parents in our ISP information intervention.

\subsection{Parents as Moderators}

We begin with Table 8 which presents interactions of our main estimates with baseline variables capturing household structure, parental involvement, and perceptions of use. Panels A and B show that the largest responses to our ISP information intervention occur in families where internet use is less likely to be observed by parents: the reductions in internet use are larger when the mother is not a "stay-at-home" mom vs. a "stay-at-home" mom (14.5MB vs. 8.5MB) and larger in single parent families vs. nonsingle parent families (26.2MB vs. 3.9 MB). This suggests that our informational intervention is most useful when it is difficult to supervise a child during the day.

In the third panel of Table 8, we use information from the baseline to construct an index of parental involvement and compare households with high vs. low levels of parental involvement. ${ }^{15}$ The reductions in Internet use associated with our ISP information intervention are substantially larger (23.1 MB vs 7.8) for parents that are highly involved vs. those less involved. This difference suggests that parental involvement might be a necessary prerequisite for using the information that we provide effectively. In other words, our informational interventions may substitute for the presence of a parent at home but are complementary to parental capacity to be involved in their children's lives. Interestingly, we do not observe much difference in the impact of our interventions by mother's education (fourth panel of Table 8), which

\footnotetext{
15 This index is based on three questions asking about parental involvement in their children's school life (helping them with homework, communicating with their teachers, etc.).
} 
suggests that our previous results are not driven by differences in human capital across families.

If, as argued earlier, our results are driven through an informational channel, then one should expect heterogeneous responses from parents who had different priors about their children's internet use at baseline, and when these priors did not match the realization of actual use. The last panel of Table 8 distinguishes between four groups of parents along two dimensions: those who had a high (low) perception of their children's internet use at baseline, and those whose children have high (low) levels of actual internet use in the period prior to the start of the interventions. ${ }^{16}$ As expected, the largest reduction in internet use is for misinformed parents with low perceptions of internet use at baseline and high actual use. The impacts are also considerably larger for parents who are correct in their prior perception that their children had high levels of internet use. ${ }^{17}$

\subsection{Parents as Mediators}

In Table 9, we use information from the endline survey to better understand how parent-child interactions might have been affected by the informational interventions. Column (1) indicates that parents who receive information about their children's internet use are 1.7 percentage points more likely (on a base of 7.2\%) to report that their children had problems with computer use. Column (2) reveals that parents who receive information are 1.5 percentage points more likely (on a base of 7\%) to report

\footnotetext{
${ }^{16}$ We define parents with high (low) perception as those who say that believe their child uses (not) "too much internet" in the baseline survey; we define parents whose children have high (low) actual use as those who have above (below) average use in the pre-treatment period.

${ }^{17}$ For the most part, the heterogeneous responses in Table 8 for the Parental Control intervention are not different along the same dimensions of parent characteristics. This is not surprising given the absence of a treatment effect for this intervention.
} 
punishing their child in response to these problems. However, in column (3), some parents are also more likely to report discussing these computer problems with their children in a calm manner. Finally, in column (4), parents who receive ISP information are more likely to report that decisions about internet use are backed by information.

The last three columns of Table 9 present indices based on variables from the endline survey that measure alternative parenting styles (authoritative, authoritarian and permissive). While these results are somewhat noisy, there is some evidence that parents in the ISP Information group are less likely to be classified as having a permissive parenting style.

Together, these results help shed light on the mechanisms underlying our main results. The results in Table 8 suggest that our informational interventions substitute for the presence of a parent at home but are complementary to parents' capacity to be involved in their children's lives. Moreover, parents who believe their children use too much internet have the largest reductions in internet use. This evidence is consistent with the view that the information helped parents better monitor and supervise their children. The results in Table 9 further suggest that our intervention may have changed the equilibrium level of internet use through increases in punishments, discussions surrounding internet use, and a less permissive parenting style.

\section{Further Results}

\subsection{Persistence}

If our informational interventions provided parents with new tools to address the challenge of monitoring and supervising their children, we would expect the main impacts to persist. On the other hand, if parents depend on the SMSs themselves to help them monitor and supervise their children, these effects would likely disappear when 
they stop receiving their SMSs. To answer this important question, we analyze the impact of our treatments during the period after the interventions had ended (i.e. the "post-treatment period").

We consider the broad patterns over time in Figure 6, which shows the treatment effects for each week in the pre-treatment period, treatment period, and post-treatment period (relative to the control group). We observe that the treatment effects remain at a similar level even after the interventions conclude in week 14. This indicates that our main impacts did persist following the treatment period. A similar picture emerges in the regression results presented in Table 10, which confirm that there are significant impacts even after the treatment ends, at roughly the same order of magnitude as the impacts during the second half of the treatment period. ${ }^{18}$ Not surprisingly, when we use our event-study framework, we do not find any significant effect during the post-treatment period when the SMSs were not actually received. These results are shown in Figure 7 which presents the event study impacts in the posttreatment period restricted to the fixed schedule sub-treatment. ${ }^{19}$

The persistence of our impacts bolster the evidence presented in section 5 , and are consistent with the notion that the ISP informational intervention may have led to persistent effects by changing the nature of parent-child interactions.

\subsection{Dynamics}

\footnotetext{
18 The experiment took place during both the vacation period (from December, 2013 to early March 2014) and the school period (from early March onwards). This has an important overlap with the analyses we perform in this section. Appendix Table A10 estimates treatment effects for the last two weeks of the vacation period and the first two weeks of the school period in order to compare the effect of the treatment while in vacation and while in school. These results suggest the treatment effects are not substantially different for the vacation and school period and, therefore, we conclude that the dynamic effects we present in this section are probably unrelated to this alternative explanation.

${ }^{19}$ We only use information for the individuals who received messages on a fixed day of the week because it is not obvious how to show "placebo" impacts in the post-treatment period for the subsample of individuals who received messages on a random day of the week.
} 
Did the impacts associated with our interventions display different dynamics during the treatment period? We begin with Figure 6, which also shows the impacts for the treatment period (relative to the control group). The impacts of the ISP information treatment build up during the first 4 weeks of treatment and then appear to stabilize through the rest of the treatment period. This pattern is confirmed in Table 10 , which presents coefficient estimates for the impact of each treatment for the first-half of the treatment (from weeks 1 to 7) and for the second half of the treatment (weeks 8 to 14).

Figure 5 presents the impacts from the event study for the first and second half of the treatment period. The immediate effects of providing ISP information were clearly stronger in the first-half of the treatment period. Appendix Table 9 presents the coefficients and standard errors corresponding to these plots. They show large decreases in internet use of approximately 13 MBs on the day the SMS was received and 20 MBs one day after receipt of the SMS. In contrast, the impacts in the second half of the sample, while still negative, are not statistically significant. Thus, the immediate effect of receiving the SMSs themselves appears to fade out midway through the treatment period, and the persistence of the aggregate impacts must be due to other changes in parent and child behavior, as described in section 5 .

Next, we decompose the heterogeneous response in the first and second half of the treatment period between the random and fixed subgroups. In Figure 8, we plot the relative impact of receiving an SMS message in an unpredictable fashion for each week in the pre-treatment, treatment and post-treatment periods. We observe that the (negative) impact becomes larger in magnitude during the second part of the treatment period. This is not surprising if it takes parents time to discern whether the messages are arriving in predictable or unpredictable fashion (parents were not informed about the manner in which the SMSs would be delivered). A similar pattern emerges in Figure 
9 where the short-term effects of the fixed and random groups are similar in the first half of the treatment period, but only observed for the random group by the second part of the treatment period

These results provide complementary evidence on why the cues associated with an SMS message have an impact in our analysis. The different dynamics of random versus fixed messages during the first and second part of the intervention are consistent with the view that the increased strength of the cue for random-schedule messages should be more relevant in the second part of the intervention after recipients on the fixed-schedule have likely become accustomed to receiving their messages on the same day every week.

\subsection{Interactions between treatments}

Finally, we consider the interaction between our main treatments that sent SMSs providing ISP Information about internet use and Parental Control software with our sub-treatments that varied whether those SMSs were received on a random or a fixed schedule. These interactions effects are displayed in Table 11 for our combined treatments and in Appendix Table 11 for the separate treatments. In both cases, we observe main effects that are similar to the ones estimated in previous tables: receiving SMSs with ISP Information about internet use leads to significantly lower internet use; receiving reminders/assistance for installing Parental Control software has a negative but statistically insignificant impact on internet use; and receiving SMSs on a random schedule leads to very large and significant reductions in internet use.

The interaction effects between ISP information and indicators for a random schedule are consistently positive, albeit not significant (a similar pattern holds with respect to the interaction between the random schedule and the Parental Control 
group). This suggests that ISP information and any cue associated with a random schedule are, if anything, substitutes and not complements. In other words, providing specific information appears to crowd out the effect of the cue associated with the message, although this effect is not significant.

\section{Conclusion}

Parents are often confronted with the challenge of supervising their children's actions. This challenge has become even more pressing with the increasing availability of internet access at home which may displace productive activities and expose students to inappropriate content. Our paper examines the role of imperfect information among parents and the potential for direct parental controls in affecting children's internet use. We designed and implemented a set of randomized experiments to test whether the intensity of children's internet use responds to the provision of specific information about children's internet use and to the offer of assistance with the installation of parental control software. The sample includes children in $7^{\text {th }}$ and $8^{\text {th }}$ grade who received free computers and 12 months of free internet through Chile's "Yo Elijo mi PC" (YEMPC) program in 2013, and we take advantage of detailed information on the intensity of internet use at the daily level from the internet service provider (ISP) which served all of the computers provided to the children in our sample.

Our results show that sending parents SMSs with information about their children's internet use leads to substantial reductions in use: households in which parents received ISP information about internet use had a significantly lower intensity of internet use during the treatment period as compared to households in the control group who received a generic SMS. We observe statistically significant reductions in use precisely on the days immediately after receiving the ISP information. Furthermore, it is 
those SMS messages indicating that children used more internet than the reference group in a specific week, which produce the largest declines in internet use.

Accordingly, the impacts of providing ISP information to parents are concentrated in the upper quintiles of the distribution of internet use. We find no impact of receiving assistance with the installation of parental control software on the intensity of internet use. Moreover, we do not observe short-term impacts of actually installing parental control software among the families that received assistance.

Taken together, these findings indicate that providing parents with specific information about their children's internet use affect behavior while providing parents with parental control software does not. The fact that the impacts of information effects persist after treatment ends suggests that our temporary intervention may have altered the equilibrium level of internet use and alleviated the problem of imperfect information in a more permanent way. Consistent with this, we find that parents who received ISP information were more likely to punish their children or discuss the problems of internet use with their children, as well as some evidence that parenting styles become less permissive.

We also find strong evidence that households who received SMSs with an unpredictable schedule experienced significantly greater reductions in internet use than those on predictable schedules, an effect similar in magnitude to the main effect associated with receiving the ISP information. In addition, we find that the SMS messages sent to the control group had short-term impacts on internet use in the first weeks of the experiment, perhaps due to the novelty of the message. These findings suggest that the cues associated with messages have an independent effect on behavior and that the strength of such cues is an important determinant of our outcomes. Thus, our study sheds light on the role of information and cues in affecting behavior. 


\section{References}

Alcott, Hunt and Todd Rogers (2014) The Short-Run and Long-Run Effects of Behavioral Interventions: Experimental Evidence from Energy Conservation" American Economic Review 104(10): 3003-3037

American Academy of Pediatrics (2016) "Policy Statement: Media Use in School-Aged Children and Adolescents", Pediatrics 138 (5).

Becker, Gary S. (1974) "A Theory of Social Interactions." Journal of Political Economy 82: 1063-94.

Becker, Gary S. (1981). A Treatise on the Family. Cambridge, Mass.: Harvard Univ. Press.

Bergman, Peter (2016) "Parent-Child Information Frictions and Human Capital Investment: Evidence from a Field Experiment Investment". Working paper.

Bergman, Peter and Eric W. Chan (2017) "Leveraging Parents: The Impact of HighFrequency Information on Student Achievement”. Working paper.

Bergstrom, Theodore C. 1989. "A Fresh Look at the Rotten Kid Theorem-and Other Household Mysteries.” Journal of Political Economy 97 (5): 1138-59.

Berlinski, Samuel, Busso, Matias, Dinkelman, Taryn and Claudia Martinez (2016) “Papás al Día: Using high frequency text messaging to reduce parent-school information gaps and improve school outcomes" Working paper.

Berry, James (2015) Child Control in Education Decisions: An Evaluation of Targeted Incentives to Learn in India. Journal of Human Resources 50(4): 1051-1080

Berns, Gregory et al. (2001) "Predictability Modulates Human Brain Response to Reward" The Journal of Neuroscience 21(8):2793-2798

Beuermann, Diether, Julian Cristia, Santiago Cueto, Ofer Malamud, and Yyannu CruzAguayo. 2015. "One Laptop per Child at Home: Short-Term Impacts from a Randomized Experiment in Peru." American Economic Journal: Applied Economics 7(2): 1-29.

Bordalo, Pedro, Nicola Gennaioli, and Andrei Shleifer (2017) "Memory, Attention, and Choice", NBER Working Paper No. 23256

Bryan, G., D. Karlan, S. Nelson (2010) “Commitment Devices” Annual Review of Economics 2: 671-698

Bursztyn, Leonardo and Lucas Coffman (2012). "The Schooling Decision: Family Preferences, Intergenerational Conflict, and Moral Hazard in the Brazilian Favelas," Journal of Political Economy 120(3): 359-397

Castleman , Benjamin L. and Lindsay Page (2017) "Parental Influences on Postsecondary Decision Making: Evidence From a Text Messaging Experiment" Educational Evaluation and Policy Analysis 39(2): 361-377 
Cunha, Nina, Guilherme Lichand, Ricardo Madeira, and Eric Bettinger (2017) "What is It About Communicating With Parents." Mimeo

de Walque, Damien and Christine Valente (2018) "Incentivizing School Attendance in the Presence of Parent-Child Information Frictions" World Bank Policy Research Working Paper 8476

Dizon-Ross, Rebecca (2018), “Parents' Beliefs and Children's Education: Experimental Evidence from Malawi,” Working paper.

Fairlie, Robert, and Jonathan Robinson. 2013. "Experimental Evidence on the Effects of Home Computers on Academic Achievement among Schoolchildren." American Economic Journal: Applied Economics 5(3): 211-240.

Fenker, Daniela B. Julietta U. Frey, Hartmut Schuetze, Dorothee Heipertz, Hans-Jochen Heinze, and Emrah Duzel (2008) "Novel Scenes Improve Recollection and Recall of Words" Journal of Cognitive Neuroscience 20(7):1250-1265

Ferster C B and B F. Skinner. (1957) Schedules of Reinforcement. Englewood Cliffs, NJ: Prentice-Hall

Finan, Frederico and Claudio Ferraz (2011) "Electoral Accountability and Corruption in Local Governments: Evidence from Audit Reports". American Economic Review 101: 1274-1311.

Gonzalez, Teresita (2017) "Efectos del Mayor Acceso a Internet Movil en el Desempeno Academico. Evidencia para Chile." Manuscript

Malamud, Ofer and Cristian Pop-Eleches, C. 2011. "Home Computer Use and the Development of Human Capital." Quarterly Journal of Economics 126: 987-1027.

Malamud, Ofer, Diether Beuermann, Julian Cristia, and Santiago Cueto. 2018 “Do Children Benefit from Internet Access? Experimental Evidence from a Developing Country" Unpublished mimeo.

OECD (2017), PISA 2015 Results (Volume III): Students' Well-Being, PISA, OECD Publishing, Paris. (http://dx.doi.org/10.1787/9789264273856-en)

Parkin, Alan J. (1997) "Human memory: Novelty, association and the brain" Current Biology 7: 768-769

Taubinsky, D. (2014) "From Intentions to Actions: A Model and Experimental Evidence of Inattentive Choice” Mimeo.

Vigdor, J., and H. Ladd., Erika Martinez 2014. "Scaling the Digital Divide: Home Computer Technology and Student Achievement." Economic Inquiry 52(3): 1103-1119.

Weinberg, Bruce (2001), "An Incentive Model of the Effect of Parental Income on Children," Journal of Political Economy 109(2): 266-280 
Table 1: Sample Size by Treatment and Subtreatment

\begin{tabular}{llccc}
\hline \hline \multicolumn{2}{c}{$\begin{array}{c}\text { Treatment } \\
\text { Group }\end{array}$} & Fixed & Random & \\
& Day & Day & Total \\
\hline$T_{1}$ & ISP & 963 & 964 & 1927 \\
$T_{2}$ & W8 & 965 & 963 & 1928 \\
$T_{3}$ & ISP + W8 & 962 & 962 & 1924 \\
$T_{0}$ & SMS-only & 964 & 964 & 1928 \\
\hline & Total & 3853 & 3854 & 7707 \\
\hline \hline
\end{tabular}

Notes: The sample was stratified by Guardian's education (No HighSchool, High School, College), Parent perception of whether the student stays too long in front of the computer (Yes or No) and Internet Use as the total MBs downloaded + uploaded between September and December (the 15th). 
Table 2: Summary Statistics

\begin{tabular}{|c|c|c|}
\hline & Mean & S.D. \\
\hline \multicolumn{3}{|l|}{ Panel A: Student Characteristics } \\
\hline MBs used (pre-treatment) & 173.97 & 210.06 \\
\hline Minutes of internet use (pre-treatment) & 186.37 & 162.81 \\
\hline Lives with mother & 0.96 & 0.20 \\
\hline Lives with father & 0.62 & 0.49 \\
\hline Lives with Brother/Sister & 0.76 & 0.42 \\
\hline Lives with Grandfather/Grandmother & 0.15 & 0.36 \\
\hline Female & 0.43 & 0.49 \\
\hline Number of siblings & 1.72 & 1.28 \\
\hline \multicolumn{3}{|l|}{ Panel B: Guardian Characteristics } \\
\hline Guardian Age & 40.42 & 7.78 \\
\hline \multicolumn{3}{|l|}{ What is your education level? } \\
\hline Elementary incomplete & 0.10 & 0.30 \\
\hline Elementary complete & 0.14 & 0.35 \\
\hline Secondary incomplete & 0.15 & 0.36 \\
\hline Secondary complete & 0.47 & 0.50 \\
\hline Higher incomplete & 0.04 & 0.20 \\
\hline Higher complete & 0.09 & 0.29 \\
\hline \multicolumn{3}{|l|}{ What is your current employment status? } \\
\hline Working full time & 0.33 & 0.47 \\
\hline Working part-time & 0.13 & 0.33 \\
\hline Not working looking for a job & 0.06 & 0.23 \\
\hline Not working not looking for a job & 0.47 & 0.50 \\
\hline Other & 0.02 & 0.14 \\
\hline
\end{tabular}

Notes: This table presents estimated means (Column 1) and standard deviations (Column 2) for students included in the experimental sample. 
Table 3: Balance by Treatment

\begin{tabular}{|c|c|c|c|c|c|}
\hline & $\begin{array}{l}(1) \\
T_{1} \\
\end{array}$ & $\begin{array}{l}(2) \\
T_{2} \\
\end{array}$ & $\begin{array}{l}(3) \\
T_{3} \\
\end{array}$ & $\begin{array}{c}(4) \\
\text { SMS-Only }\end{array}$ & $\begin{array}{c}(5) \\
\text { P-Value(F-Test) }\end{array}$ \\
\hline \multicolumn{6}{|l|}{ Panel A: Student Characteristics } \\
\hline MBs used (pre-treatment) & $\begin{array}{c}176.40 \\
(212.02)\end{array}$ & $\begin{array}{c}176.71 \\
(207.57)\end{array}$ & $\begin{array}{c}176.73 \\
(207.16)\end{array}$ & $\begin{array}{c}175.52 \\
(212.85)\end{array}$ & 0.998 \\
\hline Minutes of internet use (pre-treatment) & $\begin{array}{c}185.26 \\
(161.91)\end{array}$ & $\begin{array}{c}188.04 \\
(164.42)\end{array}$ & $\begin{array}{c}188.17 \\
(164.60)\end{array}$ & $\begin{array}{c}184.60 \\
(160.53)\end{array}$ & 0.862 \\
\hline Live with mother & $\begin{array}{c}0.95 \\
(0.21)\end{array}$ & $\begin{array}{c}0.96 \\
(0.19)\end{array}$ & $\begin{array}{c}0.97 \\
(0.18)\end{array}$ & $\begin{array}{c}0.95 \\
(0.21)\end{array}$ & 0.085 \\
\hline Live with father & $\begin{array}{c}0.62 \\
(0.49)\end{array}$ & $\begin{array}{c}0.62 \\
(0.49)\end{array}$ & $\begin{array}{c}0.61 \\
(0.49)\end{array}$ & $\begin{array}{c}0.62 \\
(0.49)\end{array}$ & 0.931 \\
\hline Live with Brother/Sister & $\begin{array}{c}0.76 \\
(0.43)\end{array}$ & $\begin{array}{c}0.78 \\
(0.42)\end{array}$ & $\begin{array}{c}0.78 \\
(0.41)\end{array}$ & $\begin{array}{c}0.75 \\
(0.43)\end{array}$ & 0.112 \\
\hline Live with Grandfather/Grandmother & $\begin{array}{c}0.16 \\
(0.37)\end{array}$ & $\begin{array}{c}0.15 \\
(0.36)\end{array}$ & $\begin{array}{c}0.15 \\
(0.36)\end{array}$ & $\begin{array}{c}0.15 \\
(0.35)\end{array}$ & 0.766 \\
\hline Female & $\begin{array}{c}0.42 \\
(0.49)\end{array}$ & $\begin{array}{c}0.42 \\
(0.49)\end{array}$ & $\begin{array}{c}0.42 \\
(0.49)\end{array}$ & $\begin{array}{c}0.45 \\
(0.50)\end{array}$ & 0.361 \\
\hline Number of siblings & $\begin{array}{c}1.69 \\
(1.25)\end{array}$ & $\begin{array}{c}1.73 \\
(1.30)\end{array}$ & $\begin{array}{c}1.73 \\
(1.31)\end{array}$ & $\begin{array}{c}1.74 \\
(1.28)\end{array}$ & 0.625 \\
\hline \multicolumn{6}{|l|}{ Panel B: Guardian Characteristics } \\
\hline Guardian Age & $\begin{array}{c}40.29 \\
(7.82)\end{array}$ & $\begin{array}{c}40.64 \\
(7.98)\end{array}$ & $\begin{array}{c}40.49 \\
(7.92)\end{array}$ & $\begin{array}{c}40.50 \\
(7.67)\end{array}$ & 0.587 \\
\hline \multicolumn{6}{|l|}{ What is your education level? } \\
\hline Elementary incomplete & $\begin{array}{c}0.09 \\
(0.29)\end{array}$ & $\begin{array}{c}0.10 \\
(0.30)\end{array}$ & $\begin{array}{c}0.10 \\
(0.30)\end{array}$ & $\begin{array}{c}0.10 \\
(0.30)\end{array}$ & 0.961 \\
\hline Elementary complete & $\begin{array}{c}0.13 \\
(0.34)\end{array}$ & $\begin{array}{c}0.14 \\
(0.35)\end{array}$ & $\begin{array}{c}0.14 \\
(0.35)\end{array}$ & $\begin{array}{c}0.15 \\
(0.35)\end{array}$ & 0.773 \\
\hline Secondary incomplete & $\begin{array}{c}0.16 \\
(0.37)\end{array}$ & $\begin{array}{c}0.15 \\
(0.36)\end{array}$ & $\begin{array}{c}0.15 \\
(0.36)\end{array}$ & $\begin{array}{c}0.15 \\
(0.36)\end{array}$ & 0.691 \\
\hline Secondary complete & $\begin{array}{c}0.47 \\
(0.50)\end{array}$ & $\begin{array}{c}0.47 \\
(0.50)\end{array}$ & $\begin{array}{c}0.47 \\
(0.50)\end{array}$ & $\begin{array}{c}0.47 \\
(0.50)\end{array}$ & 0.994 \\
\hline High incomplete & $\begin{array}{c}0.04 \\
(0.19)\end{array}$ & $\begin{array}{c}0.04 \\
(0.21)\end{array}$ & $\begin{array}{c}0.05 \\
(0.22)\end{array}$ & $\begin{array}{c}0.04 \\
(0.20)\end{array}$ & 0.329 \\
\hline High complete & $\begin{array}{c}0.10 \\
(0.30)\end{array}$ & $\begin{array}{c}0.09 \\
(0.29)\end{array}$ & $\begin{array}{c}0.09 \\
(0.28)\end{array}$ & $\begin{array}{c}0.09 \\
(0.29)\end{array}$ & 0.727 \\
\hline \multicolumn{6}{|l|}{ What is your current employment status? } \\
\hline Working full time & $\begin{array}{c}0.33 \\
(0.47)\end{array}$ & $\begin{array}{c}0.33 \\
(0.47)\end{array}$ & $\begin{array}{c}0.34 \\
(0.47)\end{array}$ & $\begin{array}{c}0.32 \\
(0.47)\end{array}$ & 0.707 \\
\hline Working part-time & $\begin{array}{c}0.13 \\
(0.33)\end{array}$ & $\begin{array}{c}0.14 \\
(0.34)\end{array}$ & $\begin{array}{c}0.13 \\
(0.33)\end{array}$ & $\begin{array}{c}0.13 \\
(0.34)\end{array}$ & 0.758 \\
\hline Not working looking for a job & $\begin{array}{c}0.05 \\
(0.22)\end{array}$ & $\begin{array}{c}0.05 \\
(0.22)\end{array}$ & $\begin{array}{c}0.06 \\
(0.23)\end{array}$ & $\begin{array}{c}0.06 \\
(0.24)\end{array}$ & 0.570 \\
\hline Not working not looking for a job & $\begin{array}{c}0.47 \\
(0.50)\end{array}$ & $\begin{array}{c}0.46 \\
(0.50)\end{array}$ & $\begin{array}{c}0.46 \\
(0.50)\end{array}$ & $\begin{array}{c}0.47 \\
(0.50)\end{array}$ & 0.790 \\
\hline Other & $\begin{array}{c}0.02 \\
(0.14)\end{array}$ & $\begin{array}{c}0.02 \\
(0.15)\end{array}$ & $\begin{array}{c}0.02 \\
(0.14)\end{array}$ & $\begin{array}{c}0.02 \\
(0.13)\end{array}$ & 0.575 \\
\hline
\end{tabular}

Note: Column 5 presents the p-value of a F test of joint differences between T1, T2 and T3 and SMS-Only. MBs used (pre-treatment) are MBs downloaded + uploaded daily from September to December 15 in the pre-treatment period. Minutes of internet use (pre-treatment) are imputed daily minutes of internet use from September to December 15 in the pre-treatment period. 
Table 4: Take-up: using Administrative Data

\begin{tabular}{|c|c|c|c|c|c|c|}
\hline & $\begin{array}{c}(1) \\
\text { SMS ISP }\end{array}$ & $\begin{array}{c}(2) \\
\text { SMS ISP }\end{array}$ & $\begin{array}{c}(3) \\
\text { SMS W8 }\end{array}$ & $\begin{array}{c}(4) \\
\text { SMS W8 }\end{array}$ & $\begin{array}{c}(5) \\
\text { W8 installed }\end{array}$ & $\begin{array}{c}(6) \\
\text { W8 installed }\end{array}$ \\
\hline \multicolumn{7}{|l|}{ Panel A: T1, T2, T3 } \\
\hline$T_{1}$ & $\begin{array}{c}0.821^{* * *} \\
(0.006)\end{array}$ & $\begin{array}{c}0.820^{* * *} \\
(0.006)\end{array}$ & $\begin{array}{c}0.000 \\
(0.005)\end{array}$ & $\begin{array}{l}-0.000 \\
(0.005)\end{array}$ & $\begin{array}{l}-0.001 \\
(0.008)\end{array}$ & $\begin{array}{l}-0.000 \\
(0.008)\end{array}$ \\
\hline$T_{2}$ & $\begin{array}{c}0.000 \\
(0.006)\end{array}$ & $\begin{array}{l}-0.001 \\
(0.006)\end{array}$ & $\begin{array}{c}0.832^{* * *} \\
(0.005)\end{array}$ & $\begin{array}{c}0.832^{* * *} \\
(0.005)\end{array}$ & $\begin{array}{c}0.135^{* * *} \\
(0.008)\end{array}$ & $\begin{array}{c}0.135^{* * *} \\
(0.008)\end{array}$ \\
\hline$T_{3}$ & $\begin{array}{c}0.816^{* * *} \\
(0.006)\end{array}$ & $\begin{array}{c}0.816^{* * *} \\
(0.006)\end{array}$ & $\begin{array}{c}0.815^{* * *} \\
(0.005)\end{array}$ & $\begin{array}{c}0.815^{* * *} \\
(0.006)\end{array}$ & $\begin{array}{c}0.156^{* * *} \\
(0.008)\end{array}$ & $\begin{array}{c}0.157^{* * *} \\
(0.008)\end{array}$ \\
\hline Observations & 7,707 & 7,707 & 7,707 & 7,707 & 7,707 & 7,707 \\
\hline Control Mean & 0 & 0 & 0 & 0 & 0 & 0 \\
\hline Additional controls & & $\mathrm{X}$ & & $\mathrm{X}$ & & $\mathrm{X}$ \\
\hline \multicolumn{7}{|c|}{ Panel B: ISP Info and Parental Controls } \\
\hline ISP Information & $\begin{array}{c}0.818^{* * *} \\
(0.004)\end{array}$ & $\begin{array}{c}0.818^{* * *} \\
(0.004)\end{array}$ & $\begin{array}{c}-0.008^{* *} \\
(0.004)\end{array}$ & $\begin{array}{c}-0.008^{* *} \\
(0.004)\end{array}$ & $\begin{array}{c}0.011^{*} \\
(0.006)\end{array}$ & $\begin{array}{c}0.011^{*} \\
(0.006)\end{array}$ \\
\hline Parental Controls & $\begin{array}{l}-0.002 \\
(0.004)\end{array}$ & $\begin{array}{l}-0.003 \\
(0.004)\end{array}$ & $\begin{array}{c}0.824^{* * *} \\
(0.004)\end{array}$ & $\begin{array}{c}0.823^{* * *} \\
(0.004)\end{array}$ & $\begin{array}{c}0.146^{* * *} \\
(0.006)\end{array}$ & $\begin{array}{c}0.146^{* * *} \\
(0.006)\end{array}$ \\
\hline Observations & 7,707 & 7,707 & 7,707 & 7,707 & 7,707 & 7,707 \\
\hline Control Mean & 0 & 0 & 0 & 0 & 0 & 0 \\
\hline Additional controls & & $\mathrm{X}$ & & $\mathrm{X}$ & & $\mathrm{X}$ \\
\hline
\end{tabular}

Note: This table presents estimated effects on take-up for different treatment groups with respect to the control group. Columns 1 and 2 present estimates on the receipt of SMSs with ISP information. Columns 3 and 4 present estimates on the reception of SMSs including an offer of help to install parental control settings. Columnd 5 and 6 present estimates on the installation of parental control settings through the call center of the experiment. We control for strata fixed effects and internet use in the pre-period in all specification. Even-numbered columns present estimates including additional baseline control variables. Control variables include the baseline values of mean of MBs of Internet use; guardian gender, age, education level and employment status; number of siblings; and dummies for family composition (indicating whether the child lives with mother, father, step-mother or father's partner, step-father or mother's partner, uncle/aunt, brother/sister, grandfather/grandmother, other relatives, and other non-relatives). Robust estimated standard errors are reported in parentheses. *** Significant at the 1 percent level. ${ }^{* *}$ Significant at the 5 percent level. ${ }^{*}$ Significant at the 10 percent level. 


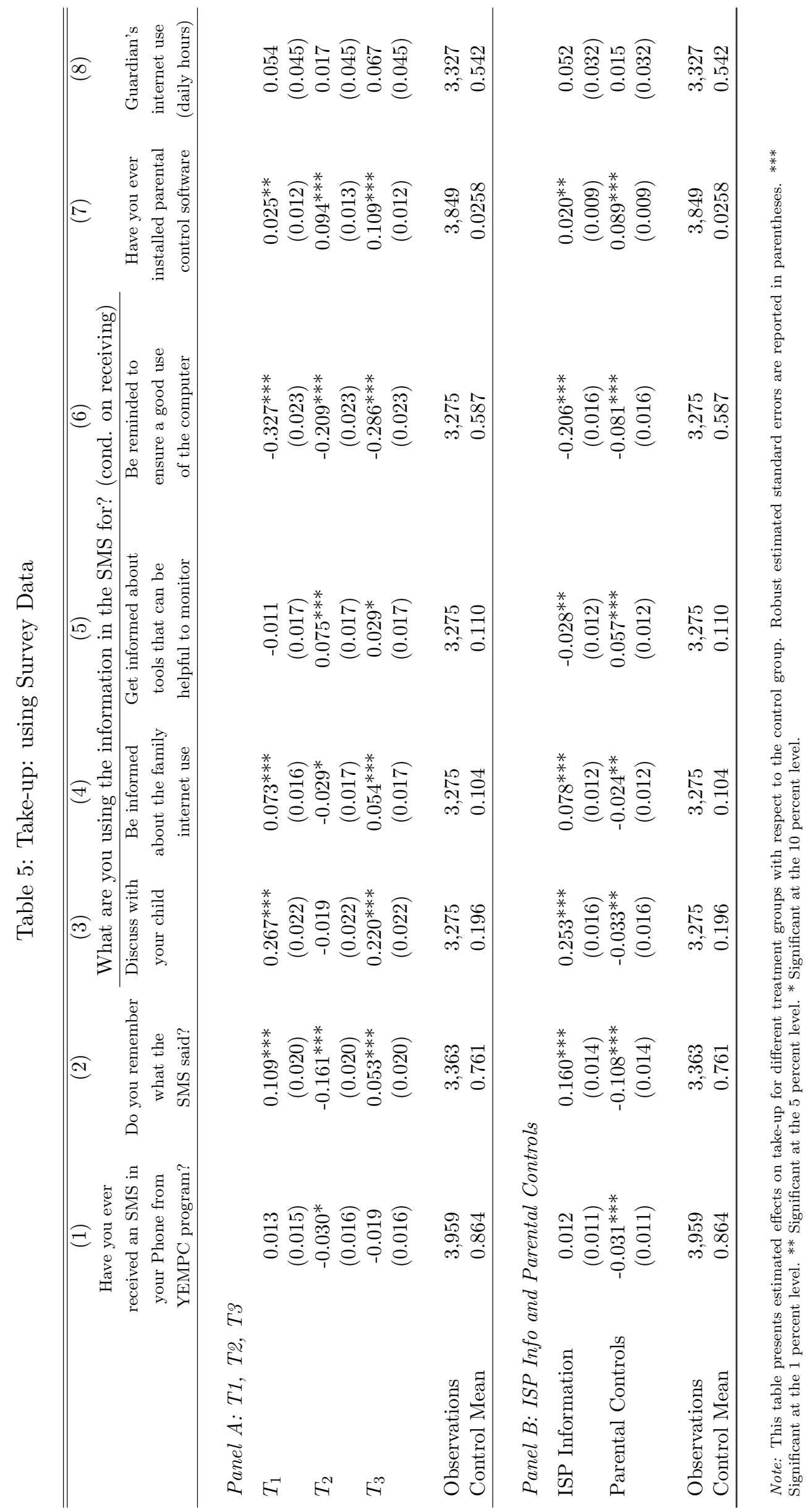


Table 6: Impact of Treatments on Intensity of Internet Use

\begin{tabular}{|c|c|c|c|c|c|c|}
\hline Period: & $\begin{array}{l}\text { (1) } \\
\text { All }\end{array}$ & $\begin{array}{l}(2) \\
\text { All }\end{array}$ & $\begin{array}{c}(3) \\
\text { Weekdays }\end{array}$ & $\begin{array}{c}(4) \\
\text { Weekdays }\end{array}$ & $\begin{array}{c}(5) \\
\text { Weekend }\end{array}$ & $\begin{array}{c}(6) \\
\text { Weekend }\end{array}$ \\
\hline \multicolumn{7}{|l|}{ Panel A: T1, T2, T3 } \\
\hline$T_{1}$ & $\begin{array}{c}-13.785^{*} \\
(7.098)\end{array}$ & $\begin{array}{c}-13.178^{*} \\
(7.086)\end{array}$ & $\begin{array}{c}-12.533^{*} \\
(7.220)\end{array}$ & $\begin{array}{c}-11.982^{*} \\
(7.215)\end{array}$ & $\begin{array}{c}-16.978^{* *} \\
(7.509)\end{array}$ & $\begin{array}{c}-16.230^{* *} \\
(7.471)\end{array}$ \\
\hline$T_{2}$ & $\begin{array}{l}-1.394 \\
(7.548)\end{array}$ & $\begin{array}{l}-0.578 \\
(7.512)\end{array}$ & $\begin{array}{l}-0.190 \\
(7.588)\end{array}$ & $\begin{array}{c}0.569 \\
(7.562)\end{array}$ & $\begin{array}{l}-4.469 \\
(8.125)\end{array}$ & $\begin{array}{c}-3.504 \\
(8.060)\end{array}$ \\
\hline$T_{3}$ & $\begin{array}{c}-12.213^{*} \\
(7.162)\end{array}$ & $\begin{array}{c}-11.744 \\
(7.148)\end{array}$ & $\begin{array}{c}-12.516^{*} \\
(7.173)\end{array}$ & $\begin{array}{c}-12.143^{*} \\
(7.168)\end{array}$ & $\begin{array}{r}-11.439 \\
(7.867)\end{array}$ & $\begin{array}{c}-10.723 \\
(7.824)\end{array}$ \\
\hline Observations & 7,707 & 7,707 & 7,707 & 7,707 & 7,707 & 7,707 \\
\hline Control Mean & 168.9 & 168.9 & 169.4 & 169.4 & 167.6 & 167.6 \\
\hline Additional controls & & $\mathrm{X}$ & & $\mathrm{X}$ & & $\mathrm{X}$ \\
\hline \multicolumn{7}{|c|}{ Panel B: ISP Information and Parental Control } \\
\hline ISP Information & $\begin{array}{c}-12.302^{* *} \\
(4.865)\end{array}$ & $\begin{array}{c}-12.172^{* *} \\
(4.848)\end{array}$ & $\begin{array}{c}-12.430^{* *} \\
(4.911)\end{array}$ & $\begin{array}{c}-12.348^{* *} \\
(4.893)\end{array}$ & $\begin{array}{c}-11.976^{* *} \\
(5.218)\end{array}$ & $\begin{array}{c}-11.724^{* *} \\
(5.200)\end{array}$ \\
\hline Parental Controls & $\begin{array}{c}0.088 \\
(4.881)\end{array}$ & $\begin{array}{c}0.429 \\
(4.855)\end{array}$ & $\begin{array}{c}-0.086 \\
(4.931)\end{array}$ & $\begin{array}{c}0.204 \\
(4.906)\end{array}$ & $\begin{array}{c}0.531 \\
(5.228)\end{array}$ & $\begin{array}{c}1.001 \\
(5.191)\end{array}$ \\
\hline Observations & 7,707 & 7,707 & 7,707 & 7,707 & 7,707 & 7,707 \\
\hline Control Mean & 168.9 & 168.9 & 169.4 & 169.4 & 167.6 & 167.6 \\
\hline Additional controls & & $\mathrm{X}$ & & $\mathrm{X}$ & & $\mathrm{X}$ \\
\hline
\end{tabular}

Note: This table presents estimated effects on Internet use measured as daily average MBs uploaded and downloaded. We control for strata fixed effects and internet use in the pre-period in all specification. Even-numbered columns present estimates including additional baseline control variables. Control variables include the baseline values of mean of MBs of Internet use; guardian gender, age, education level and employment status; number of siblings; and dummies for family composition (indicating whether the child lives with mother, father, step-mother or father's partner, step-father or mother's partner, uncle/aunt, brother/sister, grandfather/grandmother, other relatives, and other non-relatives). Robust estimated standard errors are reported in parentheses. $* * *$ Significant at the 1 percent level. ** Significant at the 5 percent level. ${ }^{*}$ Significant at the 10 percent level. 
Table 7: Impact of Sub-treatment on Intensity of Internet Use

\begin{tabular}{lcccccc}
\hline \hline & $(1)$ & $(2)$ & $(3)$ & $(4)$ & $(5)$ & $(6)$ \\
Period: & All & All & Weekdays & Weekdays & Weekend & Weekend \\
\hline \multirow{2}{*}{ Random } & & & & & & \\
& $-12.845^{* * *}$ & $-12.401^{* *}$ & $-13.588^{* * *}$ & $-13.123^{* * *}$ & $-10.950^{* *}$ & $-10.557^{* *}$ \\
& $(4.866)$ & $(4.873)$ & $(4.911)$ & $(4.921)$ & $(5.220)$ & $(5.216)$ \\
Observations & & & & & & \\
Additional controls & 7,707 & 7,707 & 7,707 & 7,707 & 7,707 & 7,707 \\
& & $\mathrm{X}$ & & $\mathrm{X}$ & & $\mathrm{X}$ \\
\hline
\end{tabular}

Note: This table presents estimated effects of the random sub-treatment (with respect to the fixed sub-treatment group) on Internet use measured as daily average MBs uploaded and downloaded. We control for strata fixed effects and internet use in the pre-period in all specification. Even-numbered columns present estimates including additional baseline control variables. Control variables include the baseline values of mean of MBs of Internet use; guardian gender, age, education level and employment status; number of siblings; and dummies for family composition (indicating whether the child lives with mother, father, step-mother or father's partner, step-father or mother's partner, uncle/aunt, brother/sister, grandfather/grandmother, other relatives, and other non-relatives). Robust estimated standard errors are reported in parentheses. ${ }^{* * *}$ Significant at the 1 percent level. ${ }^{* *}$ Significant at the 5 percent level. ${ }^{*}$ Significant at the 10 percent level. 
Table 8: Heterogeneous Treatment Effects of ISP Information

Heterogeneity:

ISP Info

Mother is or not at home

Mother at home

$-8.459$

( 6.870$)$

Mother not at home

$-14.554^{* *}$

( 7.137)

Single or not single-parent family

Single-parent family

Not single parent family

( 5.917)

Parenting index

High parenting index

$-23.110 * * *$

( 6.508$)$

Low parenting index

7.818

$(7.376)$

Mother's education

Educated mother (high school graduate or above)

$-12.661^{* *}$

( 6.066)

Uneducated mother (below high school graduate)

$-11.008$

( 7.951)

\section{Misperception}

High perception: OK

$-14.907$

$(14.143)$

High perception: Wrong

Low perception: OK

Low perception: Wrong

$-18.861^{*}$

( 9.747)

Note: This table presents heterogeneous effects of estimated effects on Internet use measured as daily average MBs uploaded and downloaded. We control for strata fixed effects and baseline variables in all specification. Baseline variables include the values of mean of MBs of Internet use in pre-treatment period; guardian gender, age, education level and employment status; number of siblings; and dummies for family composition (indicating whether the child lives with mother, father, step-mother or father's partner, step-father or mother's partner, uncle/aunt, brother/sister, grandfather/grandmother, other relatives, and other non-relatives). Robust estimated standard errors are reported in parentheses. ${ }^{* * *}$ Significant at the 1 percent level. ${ }^{* *}$ Significant at the 5 percent level. * Significant at the 10 percent level. 


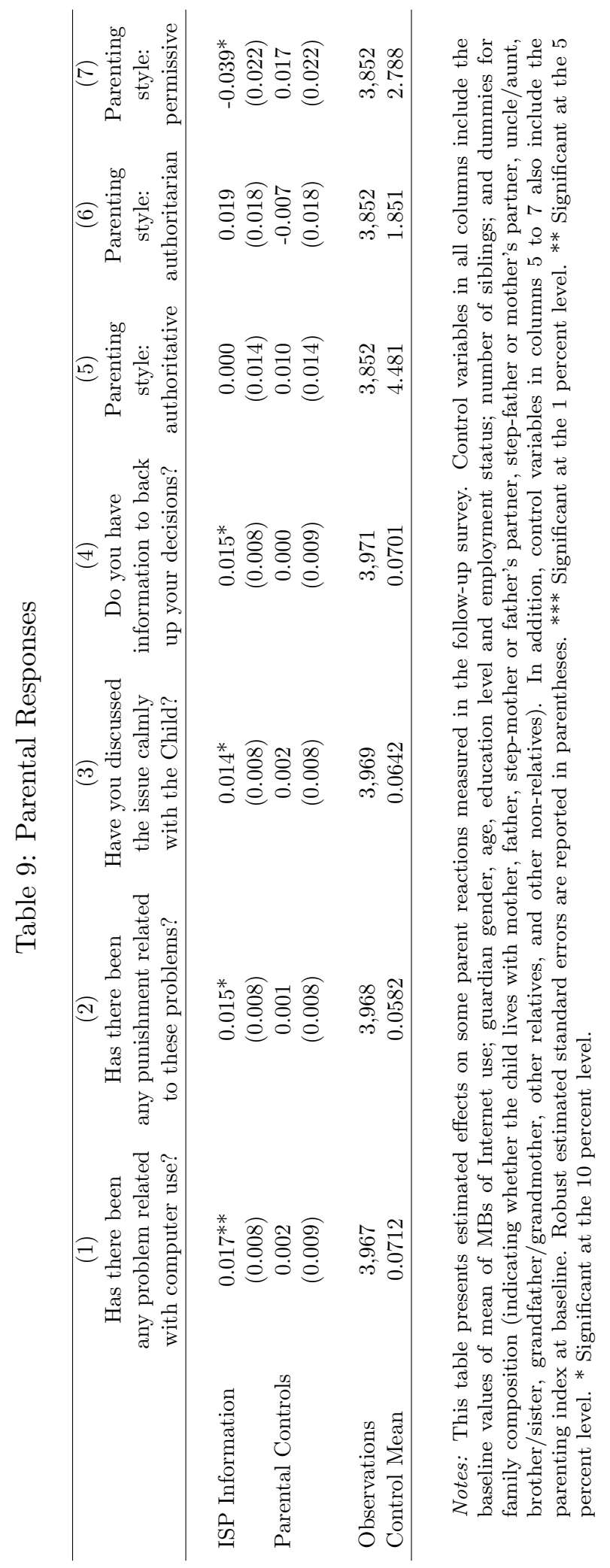


Table 10: Impact of Treatments on Intensity of Internet Use Across Periods

\begin{tabular}{|c|c|c|c|c|c|c|}
\hline Period: & $\begin{array}{l}(1) \\
\text { All }\end{array}$ & $\begin{array}{l}(2) \\
\text { All } \\
\end{array}$ & $\begin{array}{c}(3) \\
\text { Weekdays }\end{array}$ & $\begin{array}{c}(4) \\
\text { Weekdays }\end{array}$ & $\begin{array}{c}(5) \\
\text { Weekend }\end{array}$ & $\begin{array}{c}(6) \\
\text { Weekend }\end{array}$ \\
\hline \multicolumn{7}{|c|}{ Panel A: 1st Half of Treatment Period } \\
\hline ISP Information & $\begin{array}{c}-12.277^{* * *} \\
(4.408)\end{array}$ & $\begin{array}{c}-12.286^{* * *} \\
(4.386)\end{array}$ & $\begin{array}{c}-10.916^{* *} \\
(4.473)\end{array}$ & $\begin{array}{c}-10.957^{* *} \\
(4.447)\end{array}$ & $\begin{array}{c}-15.973^{* * *} \\
(4.867)\end{array}$ & $\begin{array}{c}-15.894^{* * *} \\
(4.853)\end{array}$ \\
\hline Parental Controls & $\begin{array}{c}3.329 \\
(4.404)\end{array}$ & $\begin{array}{c}3.667 \\
(4.405)\end{array}$ & $\begin{array}{c}2.833 \\
(4.470)\end{array}$ & $\begin{array}{c}3.101 \\
(4.470)\end{array}$ & $\begin{array}{c}4.674 \\
(4.866)\end{array}$ & $\begin{array}{c}5.202 \\
(4.865)\end{array}$ \\
\hline Observations & 7,707 & 7,707 & 7,707 & 7,707 & 7,707 & 7,707 \\
\hline Control Mean & 163.8 & 163.8 & 166.2 & 166.2 & 157.3 & 157.3 \\
\hline Additional controls & & $\mathrm{X}$ & & $\mathrm{X}$ & & $\mathrm{X}$ \\
\hline \multicolumn{7}{|c|}{ Panel B: 2nd Half of Treatment Period } \\
\hline ISP Information & $\begin{array}{c}-12.327^{*} \\
(6.391)\end{array}$ & $\begin{array}{c}-12.055^{*} \\
(6.375)\end{array}$ & $\begin{array}{c}-14.028^{* *} \\
(6.516)\end{array}$ & $\begin{array}{c}-13.816^{* *} \\
(6.505)\end{array}$ & $\begin{array}{l}-8.246 \\
(6.858)\end{array}$ & $\begin{array}{l}-7.831 \\
(6.827)\end{array}$ \\
\hline Parental Controls & $\begin{array}{l}-3.217 \\
(6.434)\end{array}$ & $\begin{array}{l}-2.873 \\
(6.383)\end{array}$ & $\begin{array}{l}-3.167 \\
(6.579)\end{array}$ & $\begin{array}{c}-2.854 \\
(6.523)\end{array}$ & $\begin{array}{l}-3.335 \\
(6.881)\end{array}$ & $\begin{array}{l}-2.920 \\
(6.819)\end{array}$ \\
\hline Observations & 7,707 & 7,707 & 7,707 & 7,707 & 7,707 & 7,707 \\
\hline Control Mean & 174 & 174 & 172.7 & 172.7 & 177.1 & 177.1 \\
\hline Additional controls & & $\mathrm{X}$ & & $\mathrm{X}$ & & $\mathrm{X}$ \\
\hline \multicolumn{7}{|c|}{ Panel C: Post-Treatment Period } \\
\hline ISP Information & $\begin{array}{c}-12.326^{* * *} \\
(4.471)\end{array}$ & $\begin{array}{c}-12.126^{* * *} \\
(4.452)\end{array}$ & $\begin{array}{c}-12.158^{* * *} \\
(4.402)\end{array}$ & $\begin{array}{c}-12.007^{* * *} \\
(4.383)\end{array}$ & $\begin{array}{c}-12.754^{* *} \\
(5.021)\end{array}$ & $\begin{array}{c}-12.428^{* *} \\
(4.999)\end{array}$ \\
\hline Parental Controls & $\begin{array}{c}-1.096 \\
(4.476)\end{array}$ & $\begin{array}{l}-0.717 \\
(4.455)\end{array}$ & $\begin{array}{l}-1.753 \\
(4.409)\end{array}$ & $\begin{array}{c}-1.436 \\
(4.387)\end{array}$ & $\begin{array}{c}0.575 \\
(5.028)\end{array}$ & $\begin{array}{c}1.112 \\
(5.002)\end{array}$ \\
\hline Observations & 7,707 & 7,707 & 7,707 & 7,707 & 7,707 & 7,707 \\
\hline Control Mean & 149.5 & 149.5 & 147.2 & 147.2 & 155.3 & 155.3 \\
\hline Additional controls & & $\mathrm{X}$ & & $\mathrm{X}$ & & $\mathrm{X}$ \\
\hline
\end{tabular}

Note: This table presents estimated effects on Internet use measured as daily average MBs uploaded and downloaded. We control for strata fixed effects and internet use in the pre-period in all specification. Even-numbered columns present estimates including additional baseline control variables. Control variables include the baseline values of mean of MBs of Internet use; guardian gender, age, education level and employment status; number of siblings; and dummies for family composition (indicating whether the child lives with mother, father, step-mother or father's partner, step-father or mother's partner, uncle/aunt, brother/sister, grandfather/grandmother, other relatives, and other non-relatives). Robust estimated standard errors are reported in parentheses. *** Significant at the 1 percent level. ${ }^{* *}$ Significant at the 5 percent level. ${ }^{*}$ Significant at the 10 percent level. 
Table 11: Interactions of Treatments with Sub-treatment

\begin{tabular}{lcccccc}
\hline \hline \multirow{2}{*}{ Period: } & $(1)$ & $(2)$ & $(3)$ & $(4)$ & $(5)$ & $(6)$ \\
& All & All & Weekdays & Weekdays & Weekend & Weekend \\
\hline \multirow{2}{*}{ ISP Information } & $-16.472^{* *}$ & $-15.980^{* *}$ & $-15.737^{* *}$ & $-15.291^{* *}$ & $-18.348^{* *}$ & $-17.739^{* *}$ \\
& $(7.281)$ & $(7.286)$ & $(7.438)$ & $(7.442)$ & $(7.578)$ & $(7.588)$ \\
Parental Controls & -6.493 & -5.672 & -6.920 & -6.117 & -5.404 & -4.536 \\
& $(7.302)$ & $(7.278)$ & $(7.477)$ & $(7.444)$ & $(7.564)$ & $(7.554)$ \\
Random & $-23.597^{* *}$ & $-22.340^{* *}$ & $-23.731^{* *}$ & $-22.419^{* *}$ & $-23.255^{* *}$ & $-22.140^{* *}$ \\
ISP Info $\times$ Random & $(9.337)$ & $(9.293)$ & $(9.404)$ & $(9.367)$ & $(10.093)$ & $(10.023)$ \\
& 8.332 & 7.608 & 6.607 & 5.878 & 12.736 & 12.020 \\
PC $\times$ Random & $(9.669)$ & $(9.677)$ & $(9.760)$ & $(9.773)$ & $(10.374)$ & $(10.373)$ \\
& 13.173 & 12.259 & 13.680 & 12.701 & 11.879 & 11.133 \\
Observations & $(9.705)$ & $(9.613)$ & $(9.804)$ & $(9.709)$ & $(10.394)$ & $(10.312)$ \\
Additional controls & 7,707 & 7,707 & 7,707 & 7,707 & 7,707 & 7,707 \\
\hline
\end{tabular}

Note: This table presents estimated effects on Internet use measured as daily average MBs uploaded and downloaded. Oddnumbered columns present estimates without controls and even-numbered columns present estimates including baseline control variables. Control variables include the baseline values of mean of MBs of Internet use; guardian gender, age, education level and employment status; number of siblings; and dummies for family composition (indicating whether the child lives with mother, father, step-mother or father's partner, step-father or mother's partner, uncle/aunt, brother/sister, grandfather/grandmother, other relatives, and other non-relatives). Robust estimated standard errors are reported in parentheses. ${ }^{* * *}$ Significant at the 1 percent level. ${ }^{* *}$ Significant at the 5 percent level. ${ }^{*}$ Significant at the 10 percent level. 
Figure 1: Timeline

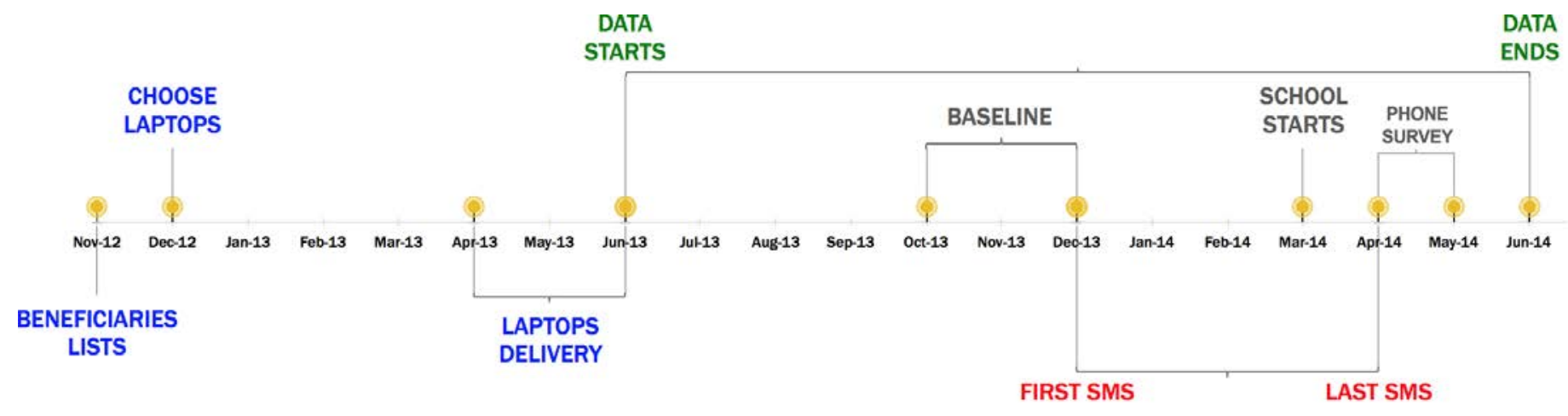


Figure 2: Quantile Regression

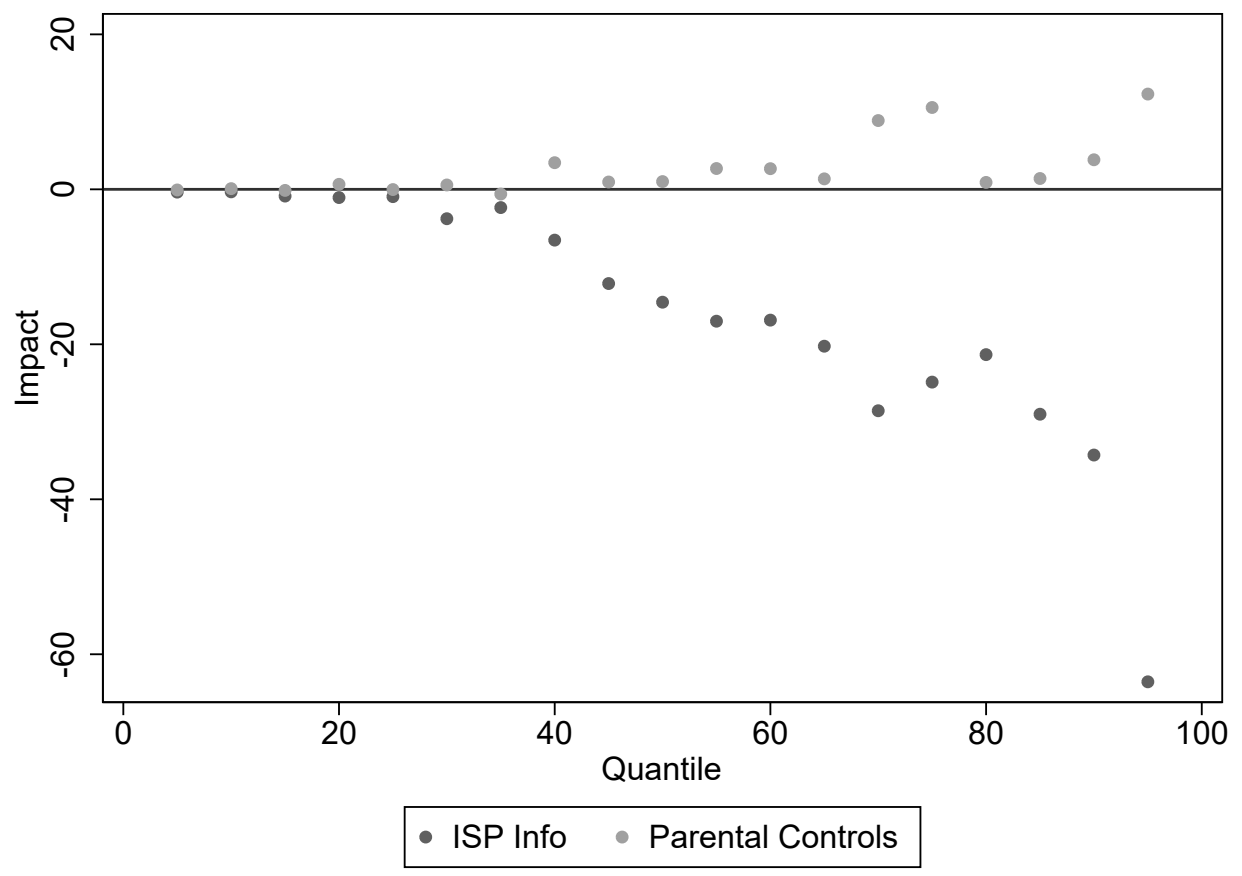

Notes: This figure presents estimated effects from the quantile regressions presented in Appendix Table 6 . 
Figure 3: Event Study for ISP Information and Parental Controls
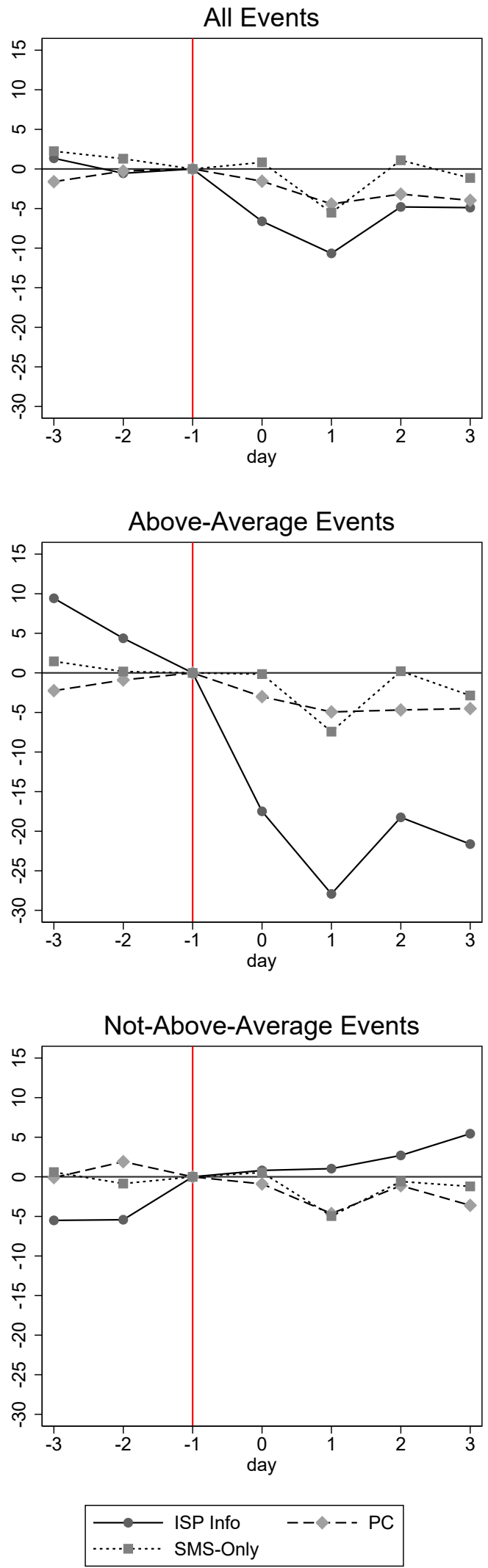

Notes: This figure presents estimated effects for each treatment group for days around the receipt of an SMS message. Day 0 marks the day on which the SMSs are received each week. Above-average events are events where the SMS said the student used more internet than the average student during the past week. See Appendix Table 6 for more details. 
Figure 4: W8 Install Event Study
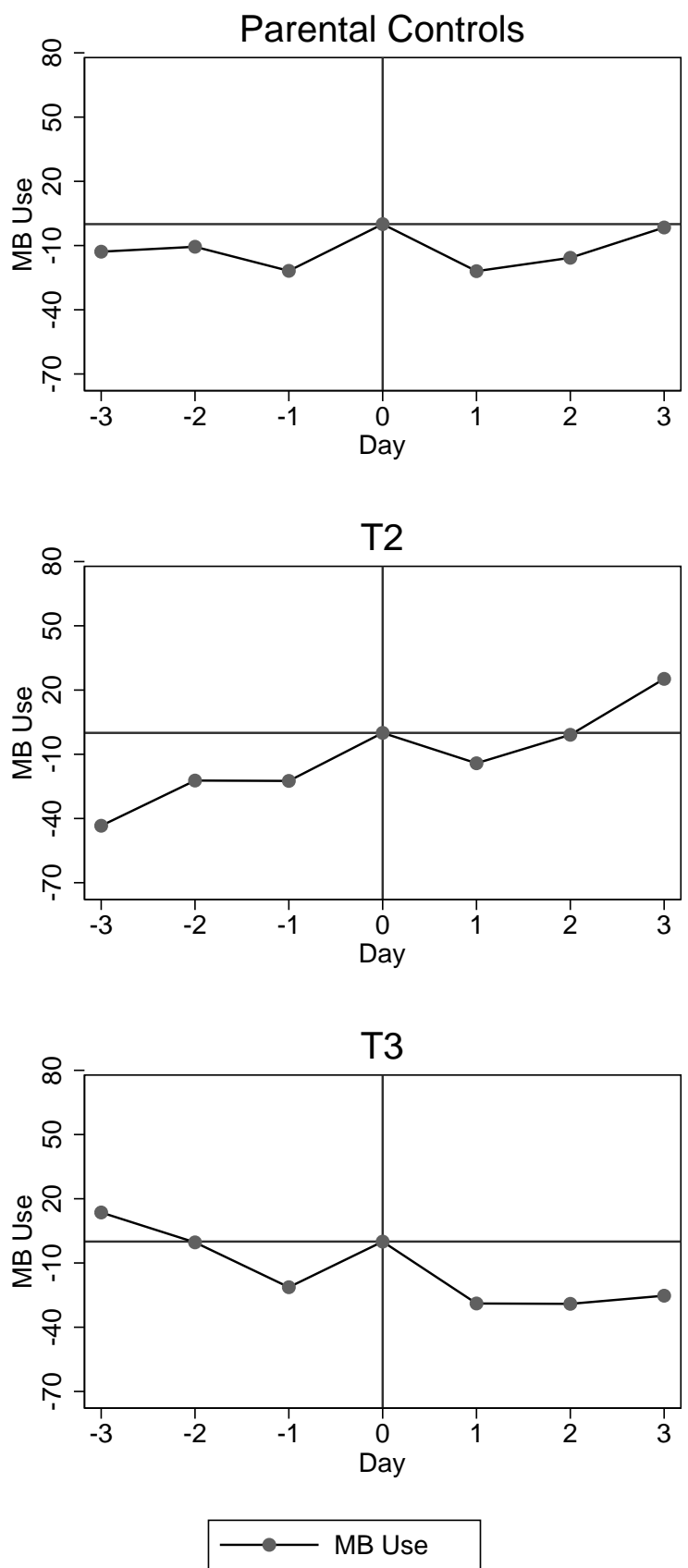

Notes: This figure presents estimated effects for the installation of the W8 parental control settings on Internet use, measured using MBs downloaded and uploaded. Day 0 marks the day on which the program was installed. We control for seasonality in every panel. See Appendix Table 7 for more details. 
Figure 5: Event Study Dynamics
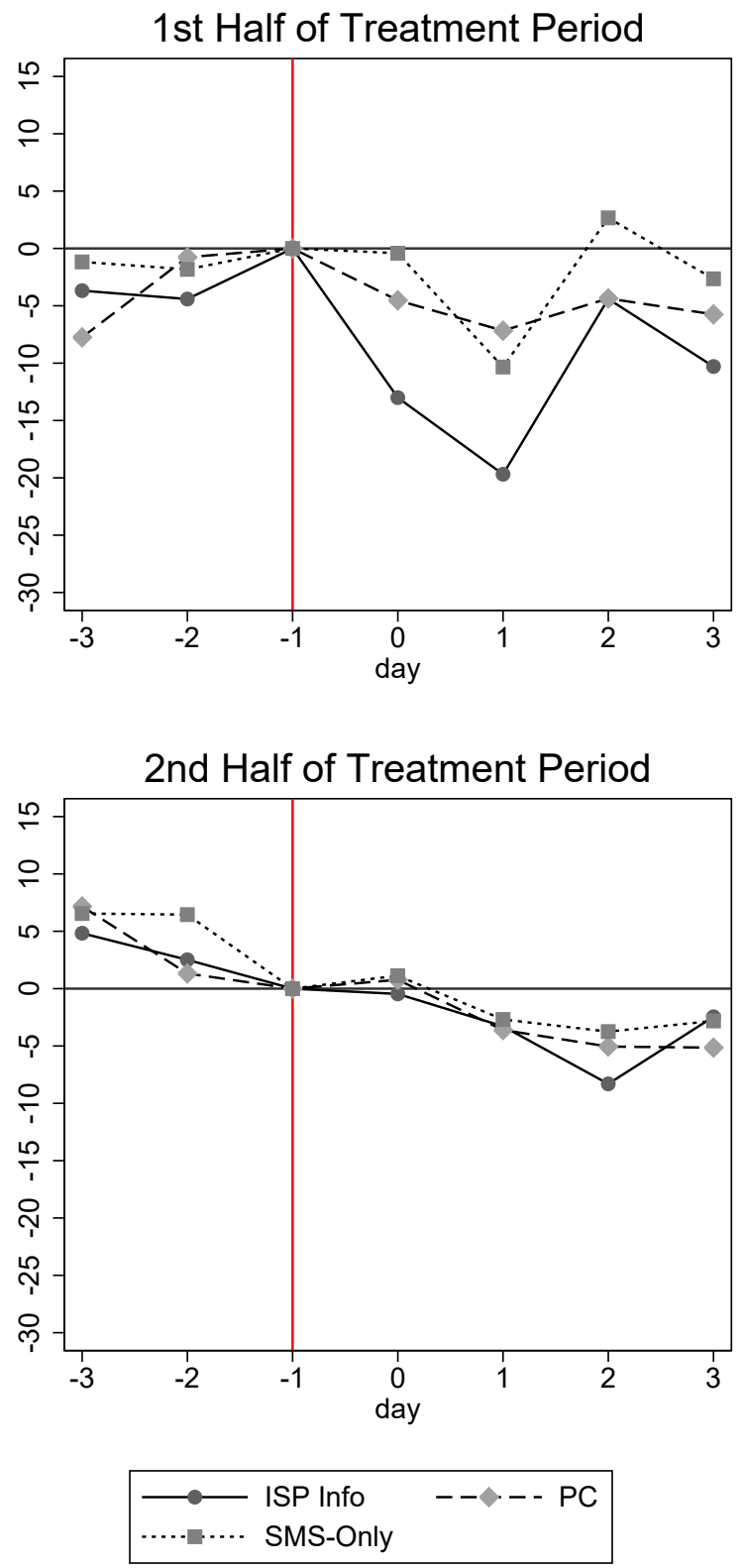

Notes: This figure presents estimated effects for each treatment group for days around the receipt of an SMS message, separating the treatment period in two. Day 0 marks the day on which the SMSs are received each week. See Appendix Table 6 for more details. 
Figure 6: Impact on MB Use Across Weeks

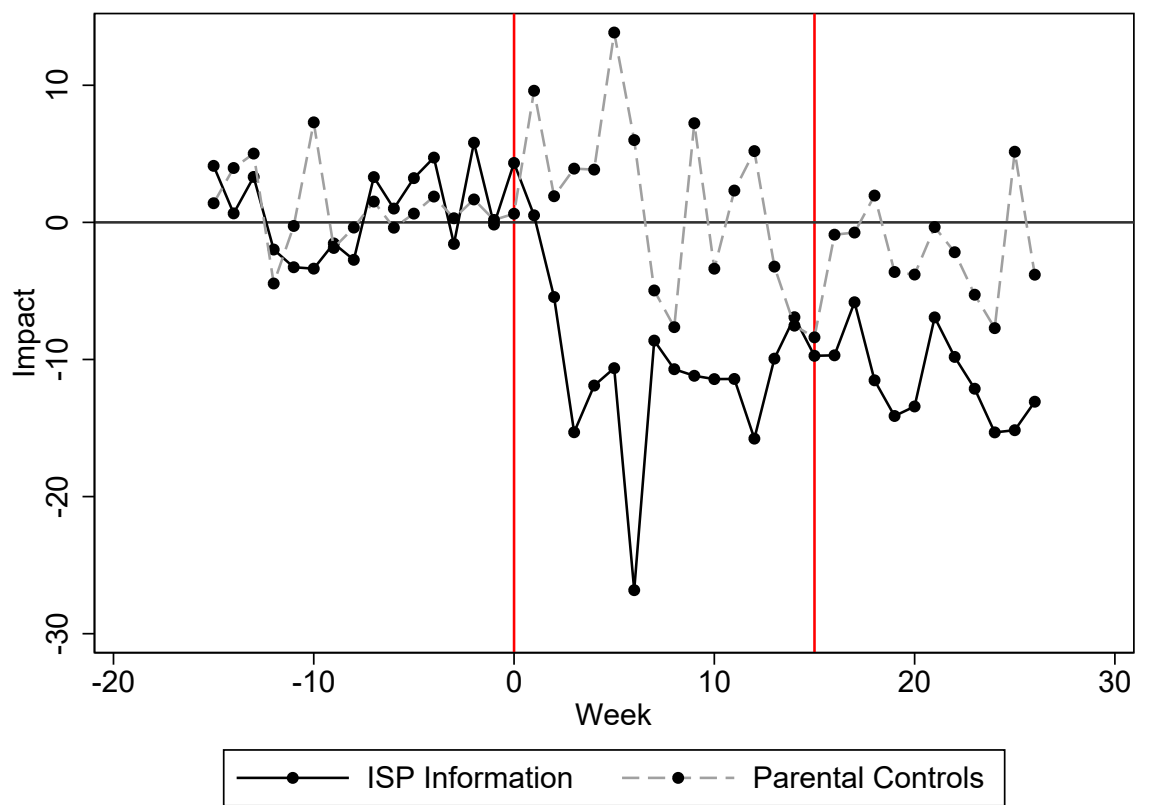

Notes: This figure presents estimated effects for each treatment group (with respect to the control group) for each week of the experiment on Internet use measured as daily average. Control variables include the baseline values of mean of MBs of Internet use; guardian gender, age, education level and employment status; number of siblings; and dummies for family composition (indicating whether the child lives with mother, father, step-mother or father's partner, step-father or mother's partner, uncle/aunt, brother/sister, grandfather/grandmother, other relatives, and other non-relatives). 
Figure 7: Event Study Dynamics and Persistence for Fixed Subgroups
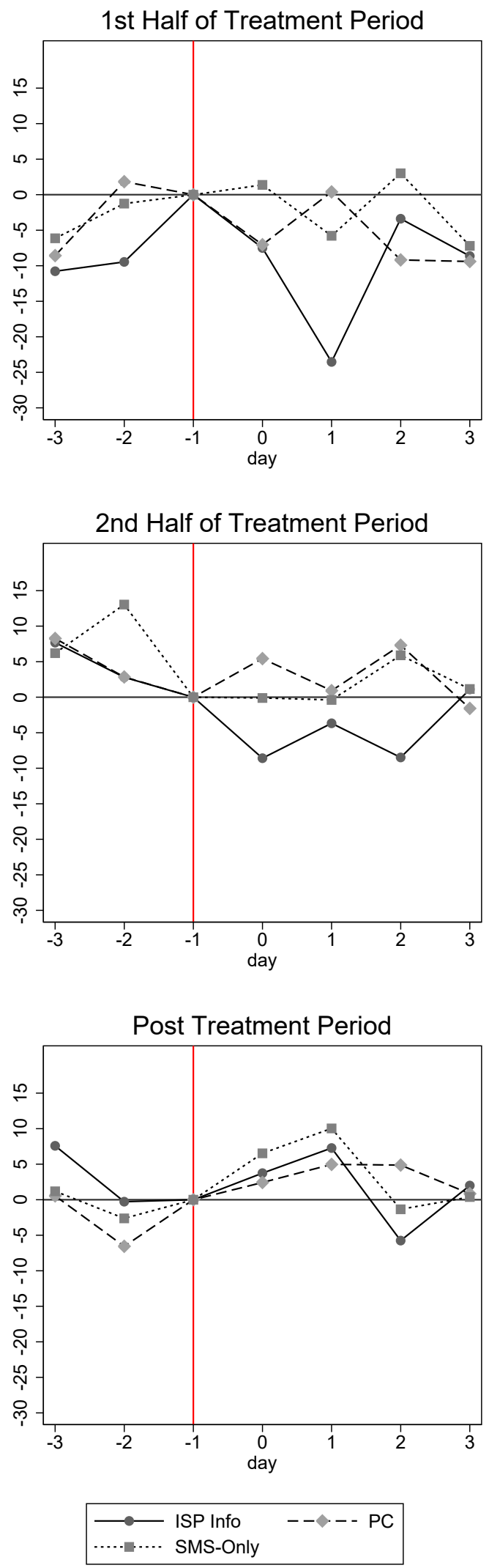

Notes: This figure presents estimated effects for each treatment group restricting the sample to the Fixed sub-group for days around the receipt of an SMS message. Day 0 marks the day on which the SMSs are received each week. See Appendix Table 11 for more details. 
Figure 8: Impact of Random on MB Use Across Weeks

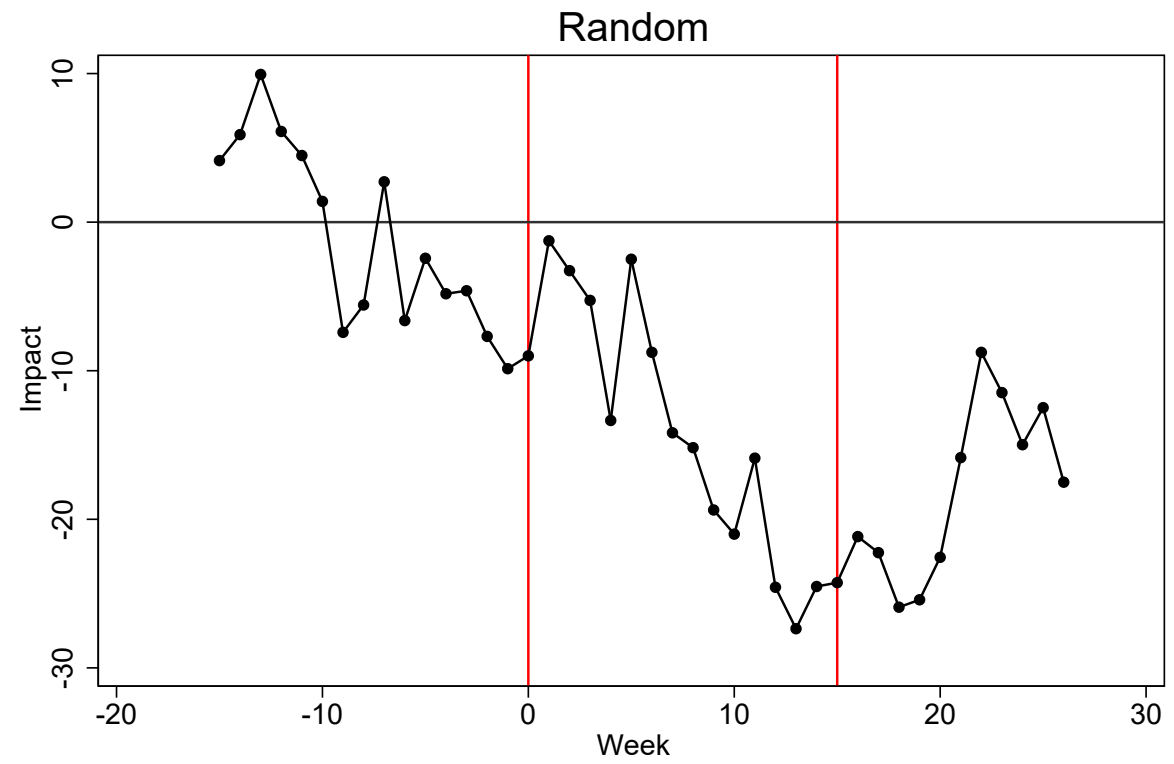

Notes: This figure presents estimated effects for Random sub-group (with respect to Fixed sub-group) for each week of the experiment on Internet use measured as daily average. Control variables include the baseline values of mean of MBs of Internet use; guardian gender, age, education level and employment status; number of siblings; and dummies for family composition (indicating whether the child lives with mother, father, step-mother or father's partner, step-father or mother's partner, uncle/aunt, brother/sister, grandfather/grandmother, other relatives, and other non-relatives). 
Figure 9: Event Study Dynamics for Random vs. Fixed
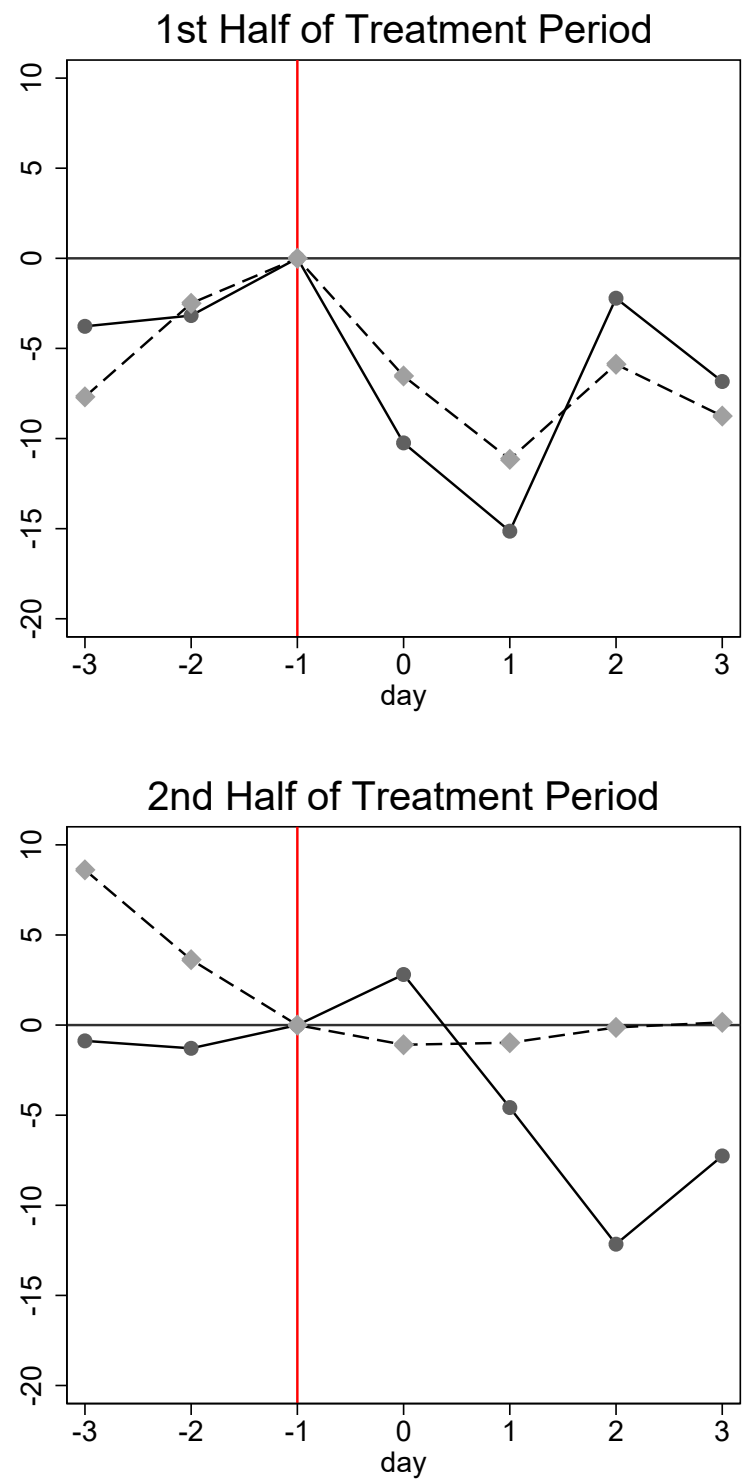

$$
\longrightarrow \text { Random }---- \text { Fixed }
$$

Notes: This figure presents estimated effects for Random and Fixed sub-groups for days around the receipt of an SMS message, separating the treatment period in two. Day 0 marks the day on which the SMSs are received each week. See Appendix Table 13 for more details. 
Table A1: Sample Comparisons

\begin{tabular}{|c|c|c|c|}
\hline Sample: & Full & Experiment & Survey \\
\hline \multicolumn{4}{|l|}{ Panel A: Student Characteristics } \\
\hline MBs used (pre-treatment) & $\begin{array}{c}180.35 \\
(213.15)\end{array}$ & $\begin{array}{c}176.34 \\
(209.88)\end{array}$ & $\begin{array}{c}177.65 \\
(216.79)\end{array}$ \\
\hline Minutes of internet use (pre-treatment) & $\begin{array}{c}189.51 \\
(164.21)\end{array}$ & $\begin{array}{c}186.52 \\
(162.85)\end{array}$ & $\begin{array}{c}185.67 \\
(162.49)\end{array}$ \\
\hline Female & $\begin{array}{c}0.41 \\
(0.49)\end{array}$ & $\begin{array}{c}0.43 \\
(0.49)\end{array}$ & $\begin{array}{c}0.43 \\
(0.49)\end{array}$ \\
\hline $\mathrm{ADHD}$ & $\begin{array}{c}14.21 \\
(3.94)\end{array}$ & $\begin{array}{c}14.48 \\
(4.14)\end{array}$ & $\begin{array}{c}14.52 \\
(4.20)\end{array}$ \\
\hline Number of siblings & $\begin{array}{c}1.77 \\
(1.32)\end{array}$ & $\begin{array}{c}1.72 \\
(1.28)\end{array}$ & $\begin{array}{c}1.69 \\
(1.26)\end{array}$ \\
\hline Rural School & $\begin{array}{c}0.15 \\
(0.36)\end{array}$ & $\begin{array}{c}0.15 \\
(0.35)\end{array}$ & $\begin{array}{c}0.14 \\
(0.35)\end{array}$ \\
\hline Computer Skills & $\begin{array}{c}8.69 \\
(2.06)\end{array}$ & $\begin{array}{c}8.72 \\
(2.02)\end{array}$ & $\begin{array}{c}8.75 \\
(2.00)\end{array}$ \\
\hline \multicolumn{4}{|l|}{ Panel B: Mother Characteristics } \\
\hline \multicolumn{4}{|l|}{ Mother's Education Level } \\
\hline Elementary incomplete & $\begin{array}{c}0.12 \\
(0.32)\end{array}$ & $\begin{array}{c}0.10 \\
(0.30)\end{array}$ & $\begin{array}{c}0.10 \\
(0.29)\end{array}$ \\
\hline Elementary complete & $\begin{array}{c}0.14 \\
(0.35)\end{array}$ & $\begin{array}{c}0.14 \\
(0.34)\end{array}$ & $\begin{array}{c}0.14 \\
(0.34)\end{array}$ \\
\hline Secondary incomplete & $\begin{array}{c}0.16 \\
(0.36)\end{array}$ & $\begin{array}{c}0.15 \\
(0.36)\end{array}$ & $\begin{array}{c}0.15 \\
(0.36)\end{array}$ \\
\hline Secondary complete & $\begin{array}{c}0.45 \\
(0.50)\end{array}$ & $\begin{array}{c}0.47 \\
(0.50)\end{array}$ & $\begin{array}{c}0.48 \\
(0.50)\end{array}$ \\
\hline Higher incomplete & $\begin{array}{c}0.03 \\
(0.18)\end{array}$ & $\begin{array}{c}0.04 \\
(0.19)\end{array}$ & $\begin{array}{c}0.04 \\
(0.19)\end{array}$ \\
\hline Higher complete & $\begin{array}{c}0.06 \\
(0.23)\end{array}$ & $\begin{array}{c}0.06 \\
(0.23)\end{array}$ & $\begin{array}{c}0.06 \\
(0.24)\end{array}$ \\
\hline \multicolumn{4}{|l|}{ Mother's Employment Status } \\
\hline Employed & $\begin{array}{c}0.34 \\
(0.47)\end{array}$ & $\begin{array}{c}0.32 \\
(0.47)\end{array}$ & $\begin{array}{c}0.30 \\
(0.46)\end{array}$ \\
\hline Unemployed & $\begin{array}{c}0.04 \\
(0.21)\end{array}$ & $\begin{array}{c}0.04 \\
(0.20)\end{array}$ & $\begin{array}{c}0.04 \\
(0.20)\end{array}$ \\
\hline Home-maker & $\begin{array}{c}0.58 \\
(0.49)\end{array}$ & $\begin{array}{c}0.61 \\
(0.49)\end{array}$ & $\begin{array}{c}0.63 \\
(0.48)\end{array}$ \\
\hline Retired & $\begin{array}{c}0.00 \\
(0.07)\end{array}$ & $\begin{array}{c}0.00 \\
(0.06)\end{array}$ & $\begin{array}{c}0.00 \\
(0.07)\end{array}$ \\
\hline \multicolumn{4}{|l|}{ Panel C: Household Characteristics } \\
\hline Rules Index & $\begin{array}{c}4.02 \\
(1.11)\end{array}$ & $\begin{array}{c}4.06 \\
(1.08)\end{array}$ & $\begin{array}{c}4.08 \\
(1.07)\end{array}$ \\
\hline Student has Computer at Home & $\begin{array}{c}0.40 \\
(0.49)\end{array}$ & $\begin{array}{c}0.41 \\
(0.49)\end{array}$ & $\begin{array}{c}0.42 \\
(0.49)\end{array}$ \\
\hline Student has Internet at Home & $\begin{array}{c}0.24 \\
(0.43) \\
\end{array}$ & $\begin{array}{c}0.25 \\
(0.43) \\
\end{array}$ & $\begin{array}{c}0.25 \\
(0.43) \\
\end{array}$ \\
\hline Sample Size & 29833 & 7707 & 5001 \\
\hline
\end{tabular}

Note: This table presents estimated means for students in the YEMPC program who applied for a computer with internet connection (Column 1), students in the experimental sample (Column 2), and students in the sample of the phone survey (Column 3). Estimated standard deviations are reported in parentheses. 
Table A2: Balance by Sub-treatment

\begin{tabular}{|c|c|c|c|}
\hline & $\begin{array}{c}(1) \\
\text { Random }\end{array}$ & $\begin{array}{c}(2) \\
\text { Fixed }\end{array}$ & $\begin{array}{c}(3) \\
\text { P-Value }\end{array}$ \\
\hline \multicolumn{4}{|l|}{ Panel A: Student Characteristics } \\
\hline MBs used (pre-treatment) & $\begin{array}{c}175.71 \\
(205.91)\end{array}$ & $\begin{array}{l}176.15 \\
(212.80)\end{array}$ & 0.791 \\
\hline Minutes of internet use (pre-treatment) & $\begin{array}{c}186.12 \\
(162.75)\end{array}$ & $\begin{array}{c}186.54 \\
(162.87)\end{array}$ & 0.832 \\
\hline Lives with mother & $\begin{array}{c}0.96 \\
(0.20)\end{array}$ & $\begin{array}{c}0.96 \\
(0.19)\end{array}$ & 0.497 \\
\hline Lives with father & $\begin{array}{c}0.61 \\
(0.49)\end{array}$ & $\begin{array}{c}0.62 \\
(0.48)\end{array}$ & 0.113 \\
\hline Lives with Brother/Sister & $\begin{array}{c}0.76 \\
(0.43)\end{array}$ & $\begin{array}{c}0.77 \\
(0.42)\end{array}$ & 0.296 \\
\hline Lives with Grandfather/Grandmother & $\begin{array}{c}0.15 \\
(0.36)\end{array}$ & $\begin{array}{c}0.15 \\
(0.36)\end{array}$ & 0.444 \\
\hline Female & $\begin{array}{c}0.43 \\
(0.49)\end{array}$ & $\begin{array}{c}0.42 \\
(0.49)\end{array}$ & 0.757 \\
\hline Number of siblings & $\begin{array}{c}1.71 \\
(1.28)\end{array}$ & $\begin{array}{l}1.72 \\
(1.27)\end{array}$ & 0.519 \\
\hline \multicolumn{4}{|l|}{ Panel B: Guardian Characteristics } \\
\hline Guardian Age & $\begin{array}{c}40.58 \\
(8.15)\end{array}$ & $\begin{array}{c}40.30 \\
(7.52)\end{array}$ & 0.262 \\
\hline \multicolumn{4}{|l|}{ What is your education level? } \\
\hline Elementary incomplete & $\begin{array}{c}0.10 \\
(0.30)\end{array}$ & $\begin{array}{c}0.10 \\
(0.30)\end{array}$ & 0.443 \\
\hline Elementary complete & $\begin{array}{c}0.14 \\
(0.35)\end{array}$ & $\begin{array}{c}0.14 \\
(0.35)\end{array}$ & 0.866 \\
\hline Secondary incomplete & $\begin{array}{c}0.15 \\
(0.36)\end{array}$ & $\begin{array}{c}0.16 \\
(0.36)\end{array}$ & 0.525 \\
\hline Secondary complete & $\begin{array}{c}0.47 \\
(0.50)\end{array}$ & $\begin{array}{c}0.47 \\
(0.50)\end{array}$ & 0.990 \\
\hline Higher incomplete & $\begin{array}{c}0.04 \\
(0.19)\end{array}$ & $\begin{array}{c}0.05 \\
(0.21)\end{array}$ & 0.072 \\
\hline Higher complete & $\begin{array}{c}0.10 \\
(0.30)\end{array}$ & $\begin{array}{c}0.09 \\
(0.29)\end{array}$ & 0.162 \\
\hline \multicolumn{4}{|l|}{ What is your current employment status? } \\
\hline Working full time & $\begin{array}{c}0.33 \\
(0.47)\end{array}$ & $\begin{array}{c}0.32 \\
(0.47)\end{array}$ & 0.374 \\
\hline Working part-time & $\begin{array}{c}0.13 \\
(0.33)\end{array}$ & $\begin{array}{c}0.13 \\
(0.34)\end{array}$ & 0.342 \\
\hline Not working looking for a job & $\begin{array}{c}0.06 \\
(0.23)\end{array}$ & $\begin{array}{c}0.06 \\
(0.23)\end{array}$ & 0.515 \\
\hline Not working not looking for a job & $\begin{array}{c}0.46 \\
(0.50)\end{array}$ & $\begin{array}{c}0.48 \\
(0.50)\end{array}$ & 0.289 \\
\hline Other & $\begin{array}{c}0.02 \\
(0.15)\end{array}$ & $\begin{array}{c}0.02 \\
(0.13)\end{array}$ & 0.049 \\
\hline
\end{tabular}

Note: This table presents estimated differences between students in the different experimental groups. Columns 1 and 2 present means and stadard deviations in parentheses. Column 3 presents the p-value of a t-test for differences between the Random day and Fixed day groups. 
Table A3: Balance by Treatment for the Follow-up Survey Sample

\begin{tabular}{|c|c|c|c|c|c|}
\hline & $\begin{array}{l}(1) \\
T_{1} \\
\end{array}$ & $\begin{array}{l}(2) \\
T_{2}\end{array}$ & $\begin{array}{l}(3) \\
T_{3}\end{array}$ & $\begin{array}{c}(4) \\
\text { SMS-Only }\end{array}$ & $\begin{array}{c}(5) \\
\text { P-Value(F-Test) }\end{array}$ \\
\hline \multicolumn{6}{|l|}{ Panel A: Student Characteristics } \\
\hline MBs used (pre-treatment) & $\begin{array}{l}172.22 \\
(212.34)\end{array}$ & $\begin{array}{c}182.96 \\
(217.43)\end{array}$ & $\begin{array}{c}174.10 \\
(201.26)\end{array}$ & $\begin{array}{c}184.84 \\
(235.60)\end{array}$ & 0.472 \\
\hline Minutes of internet use (pre-treatment) & $\begin{array}{c}180.47 \\
(159.27)\end{array}$ & $\begin{array}{c}191.39 \\
(166.27)\end{array}$ & $\begin{array}{c}185.34 \\
(162.66)\end{array}$ & $\begin{array}{c}187.61 \\
(162.93)\end{array}$ & 0.505 \\
\hline Lives with mother & $\begin{array}{l}0.96 \\
(0.19)\end{array}$ & $\begin{array}{l}0.97 \\
(0.17)\end{array}$ & $\begin{array}{l}0.97 \\
(0.17)\end{array}$ & $\begin{array}{l}0.95 \\
(0.22)\end{array}$ & 0.041 \\
\hline Lives with father & $\begin{array}{c}0.65 \\
(0.48)\end{array}$ & $\begin{array}{c}0.65 \\
(0.48)\end{array}$ & $\begin{array}{c}0.64 \\
(0.48)\end{array}$ & $\begin{array}{c}0.62 \\
(0.49)\end{array}$ & 0.345 \\
\hline Lives with Brother/Sister & $\begin{array}{c}0.77 \\
(0.42)\end{array}$ & $\begin{array}{c}0.79 \\
(0.41)\end{array}$ & $\begin{array}{c}0.80 \\
(0.40)\end{array}$ & $\begin{array}{c}0.74 \\
(0.44)\end{array}$ & 0.030 \\
\hline Lives with Grandfather/Grandmother & $\begin{array}{c}0.16 \\
(0.37)\end{array}$ & $\begin{array}{c}0.14 \\
(0.35)\end{array}$ & $\begin{array}{c}0.14 \\
(0.35)\end{array}$ & $\begin{array}{c}0.15 \\
(0.36)\end{array}$ & 0.637 \\
\hline Female & $\begin{array}{c}0.42 \\
(0.49)\end{array}$ & $\begin{array}{c}0.42 \\
(0.49)\end{array}$ & $\begin{array}{c}0.42 \\
(0.49)\end{array}$ & $\begin{array}{c}0.46 \\
(0.50)\end{array}$ & 0.205 \\
\hline Number of siblings & $\begin{array}{c}1.62 \\
(1.20)\end{array}$ & $\begin{array}{c}1.75 \\
(1.30)\end{array}$ & $\begin{array}{c}1.74 \\
(1.33)\end{array}$ & $\begin{array}{c}1.71 \\
(1.28)\end{array}$ & 0.109 \\
\hline \multicolumn{6}{|l|}{ Panel B: Guardian Characteristics } \\
\hline Guardian Age & $\begin{array}{c}40.54 \\
(7.62)\end{array}$ & $\begin{array}{c}40.47 \\
(7.26)\end{array}$ & $\begin{array}{c}40.54 \\
(7.79)\end{array}$ & $\begin{array}{c}40.85 \\
(7.77)\end{array}$ & 0.693 \\
\hline \multicolumn{6}{|l|}{ What is your education level? } \\
\hline Elementary incomplete & $\begin{array}{c}0.09 \\
(0.28)\end{array}$ & $\begin{array}{c}0.09 \\
(0.29)\end{array}$ & $\begin{array}{c}0.10 \\
(0.30)\end{array}$ & $\begin{array}{c}0.09 \\
(0.29)\end{array}$ & 0.856 \\
\hline Elementary complete & $\begin{array}{c}0.12 \\
(0.33)\end{array}$ & $\begin{array}{c}0.14 \\
(0.35)\end{array}$ & $\begin{array}{c}0.15 \\
(0.36)\end{array}$ & $\begin{array}{c}0.16 \\
(0.36)\end{array}$ & 0.139 \\
\hline Secondary incomplete & $\begin{array}{c}0.17 \\
(0.37)\end{array}$ & $\begin{array}{c}0.16 \\
(0.37)\end{array}$ & $\begin{array}{c}0.14 \\
(0.34)\end{array}$ & $\begin{array}{c}0.16 \\
(0.37)\end{array}$ & 0.315 \\
\hline Secondary complete & $\begin{array}{c}0.49 \\
(0.50)\end{array}$ & $\begin{array}{c}0.48 \\
(0.50)\end{array}$ & $\begin{array}{l}0.48 \\
(0.50)\end{array}$ & $\begin{array}{c}0.46 \\
(0.50)\end{array}$ & 0.724 \\
\hline Higher incomplete & $\begin{array}{c}0.03 \\
(0.17)\end{array}$ & $\begin{array}{c}0.04 \\
(0.20)\end{array}$ & $\begin{array}{c}0.04 \\
(0.21)\end{array}$ & $\begin{array}{c}0.03 \\
(0.18)\end{array}$ & 0.290 \\
\hline Higher complete & $\begin{array}{c}0.11 \\
(0.31)\end{array}$ & $\begin{array}{c}0.09 \\
(0.29)\end{array}$ & $\begin{array}{c}0.09 \\
(0.29)\end{array}$ & $\begin{array}{c}0.09 \\
(0.29)\end{array}$ & 0.543 \\
\hline \multicolumn{6}{|l|}{ What is your current employment status? } \\
\hline Working full time & $\begin{array}{c}0.31 \\
(0.46)\end{array}$ & $\begin{array}{c}0.30 \\
(0.46)\end{array}$ & $\begin{array}{c}0.31 \\
(0.46)\end{array}$ & $\begin{array}{c}0.29 \\
(0.45)\end{array}$ & 0.632 \\
\hline Working part-time & $\begin{array}{c}0.12 \\
(0.33)\end{array}$ & $\begin{array}{c}0.14 \\
(0.34)\end{array}$ & $\begin{array}{c}0.13 \\
(0.33)\end{array}$ & $\begin{array}{c}0.14 \\
(0.35)\end{array}$ & 0.510 \\
\hline Not working looking for a job & $\begin{array}{c}0.05 \\
(0.22)\end{array}$ & $\begin{array}{c}0.05 \\
(0.23)\end{array}$ & $\begin{array}{c}0.06 \\
(0.23)\end{array}$ & $\begin{array}{c}0.05 \\
(0.22)\end{array}$ & 0.916 \\
\hline Not working not looking for a job & $\begin{array}{c}0.50 \\
(0.50)\end{array}$ & $\begin{array}{c}0.49 \\
(0.50)\end{array}$ & $\begin{array}{c}0.48 \\
(0.50)\end{array}$ & $\begin{array}{c}0.50 \\
(0.50)\end{array}$ & 0.809 \\
\hline Other & $\begin{array}{c}0.02 \\
(0.14)\end{array}$ & $\begin{array}{c}0.02 \\
(0.14)\end{array}$ & $\begin{array}{c}0.02 \\
(0.15)\end{array}$ & $\begin{array}{c}0.01 \\
(0.12)\end{array}$ & 0.572 \\
\hline
\end{tabular}

Note: This table presents estimated differences between students in the different experimental groups who participated in the follow-up telephone survey. Columns 1 to 4 present means and stadard deviations in parentheses. Column 5 presents the p-value of a of joint test for differences between the T1, T2 and T3 and SMS-only groups. 
Table A4: Take-up: Extensive Margin using Administrative Data

\begin{tabular}{lcccc}
\hline & $(1)$ & $(2)$ & $(3)$ & $(4)$ \\
& SMS ISP & SMS ISP & SMS W8 & SMS W8 \\
\hline \multirow{2}{*}{$T_{1}$} & $0.976^{* * *}$ & $0.975^{* * *}$ & 0.000 & -0.000 \\
& $(0.004)$ & $(0.004)$ & $(0.004)$ & $(0.004)$ \\
$T_{2}$ & 0.000 & -0.000 & $0.978^{* * *}$ & $0.978^{* * *}$ \\
& $(0.004)$ & $(0.004)$ & $(0.004)$ & $(0.004)$ \\
$T_{3}$ & $0.967^{* * *}$ & $0.967^{* * *}$ & $0.967^{* * *}$ & $0.967^{* * *}$ \\
& $(0.004)$ & $(0.004)$ & $(0.004)$ & $(0.004)$ \\
& & & & \\
Observations & 7,707 & 7,707 & 7,707 & 7,707 \\
Additional Controls & & $\mathrm{X}$ & & $\mathrm{X}$ \\
Control Mean & 0 & 0 & 0 & 0 \\
\hline
\end{tabular}

Note: This table presents estimated effects for different treatment groups with respect to the control group. Columns 1 and 2 present estimates on the reception of at least one SMS including ISP information. Columns 3 and 4 present estimates on the reception of at least one SMS including an offer of help to install parental control settings. Odd-numbered columns present estimates controlling for MB Use at baseline and even-numbered columns present estimates including all baseline control variables. Control variables include the baseline values of mean of MBs of Internet use; guardian gender, age, education level and employment status; number of siblings; and dummies for family composition (indicating whether the child lives with mother, father, stepmother or father's partner, step-father or mother's partner, uncle/aunt, brother/sister, grandfather/grandmother, other relatives, and other non-relatives). Robust estimated standard errors are reported in parentheses. ${ }^{* *}$ Significant at the 1 percent level. ${ }^{* *}$ Significant at the 5 percent level. * Significant at the 10 percent level. 
Table A5: Impact of Treatments on Time of Internet Use

\begin{tabular}{|c|c|c|c|c|c|c|}
\hline Period: & $\begin{array}{l}\text { (1) } \\
\text { All }\end{array}$ & $\begin{array}{l}(2) \\
\text { All }\end{array}$ & $\begin{array}{c}(3) \\
\text { Weekdays }\end{array}$ & $\begin{array}{c}(4) \\
\text { Weekdays }\end{array}$ & $\begin{array}{c}(5) \\
\text { Weekend }\end{array}$ & $\begin{array}{c}(6) \\
\text { Weekend }\end{array}$ \\
\hline \multicolumn{7}{|l|}{ Panel A: T1, T2, T3 } \\
\hline$T_{1}$ & $\begin{array}{c}-7.910^{* *} \\
(3.389)\end{array}$ & $\begin{array}{c}-7.641^{* *} \\
(3.388)\end{array}$ & $\begin{array}{c}-7.658^{* *} \\
(3.374)\end{array}$ & $\begin{array}{c}-7.360^{* *} \\
(3.373)\end{array}$ & $\begin{array}{c}-8.553^{* *} \\
(3.599)\end{array}$ & $\begin{array}{c}-8.356^{* *} \\
(3.599)\end{array}$ \\
\hline$T_{2}$ & $\begin{array}{c}0.529 \\
(3.459)\end{array}$ & $\begin{array}{c}0.834 \\
(3.459)\end{array}$ & $\begin{array}{c}0.548 \\
(3.435)\end{array}$ & $\begin{array}{c}0.879 \\
(3.437)\end{array}$ & $\begin{array}{c}0.479 \\
(3.700)\end{array}$ & $\begin{array}{c}0.720 \\
(3.697)\end{array}$ \\
\hline$T_{3}$ & $\begin{array}{c}-5.789^{*} \\
(3.380)\end{array}$ & $\begin{array}{l}-5.507 \\
(3.386)\end{array}$ & $\begin{array}{c}-5.998^{*} \\
(3.345)\end{array}$ & $\begin{array}{c}-5.688^{*} \\
(3.351)\end{array}$ & $\begin{array}{l}-5.257 \\
(3.647)\end{array}$ & $\begin{array}{l}-5.045 \\
(3.651)\end{array}$ \\
\hline Observations & 7,707 & 7,707 & 7,707 & 7,707 & 7,707 & 7,707 \\
\hline Control Mean & 145.9 & 145.9 & 145.7 & 145.7 & 146.6 & 146.6 \\
\hline Additional controls & & $\mathrm{X}$ & & $\mathrm{X}$ & & $\mathrm{X}$ \\
\hline \multicolumn{7}{|c|}{ Panel B: ISP Information and Parental Control } \\
\hline ISP Information & $\begin{array}{c}-7.114^{* * *} \\
(2.388)\end{array}$ & $\begin{array}{c}-6.991^{* * *} \\
(2.389)\end{array}$ & $\begin{array}{c}-7.102^{* * *} \\
(2.370)\end{array}$ & $\begin{array}{c}-6.963^{* * *} \\
(2.370)\end{array}$ & $\begin{array}{c}-7.145^{* * *} \\
(2.558)\end{array}$ & $\begin{array}{c}-7.060^{* * *} \\
(2.560)\end{array}$ \\
\hline Parental Controls & $\begin{array}{c}1.324 \\
(2.389)\end{array}$ & $\begin{array}{c}1.484 \\
(2.393)\end{array}$ & $\begin{array}{c}1.104 \\
(2.370)\end{array}$ & $\begin{array}{c}1.275 \\
(2.375)\end{array}$ & $\begin{array}{c}1.886 \\
(2.560)\end{array}$ & $\begin{array}{c}2.016 \\
(2.562)\end{array}$ \\
\hline Observations & 7,707 & 7,707 & 7,707 & 7,707 & 7,707 & 7,707 \\
\hline Control Mean & 145.9 & 145.9 & 145.7 & 145.7 & 146.6 & 146.6 \\
\hline Additional controls & & $\mathrm{X}$ & & $\mathrm{X}$ & & $\mathrm{X}$ \\
\hline
\end{tabular}

Note: This table presents estimated effects on Internet use measured as predicted time connected to Internet. Odd-numbered columns present estimates controlling for time use at baseline and even-numbered columns present estimates including all baseline control variables. Control variables include the baseline values of mean of MBs of Internet use; guardian gender, age, education level and employment status; number of siblings; and dummies for family composition (indicating whether the child lives with mother, father, step-mother or father's partner, step-father or mother's partner, uncle/aunt, brother/sister, grandfather/grandmother, other relatives, and other non-relatives). Robust estimated standard errors are reported in parentheses. *** Significant at the 1 percent level. ** Significant at the 5 percent level. * Significant at the 10 percent level. 
Table A6: Quantile Regressions

\begin{tabular}{|c|c|c|}
\hline Heterogeneity: & $\begin{array}{c}(1) \\
\text { ISP Info }\end{array}$ & $\begin{array}{l}(2) \\
P C\end{array}$ \\
\hline \multirow[t]{2}{*}{ Q5 } & $-0.360^{*}$ & -0.080 \\
\hline & $(0.210)$ & $(0.157)$ \\
\hline \multirow[t]{2}{*}{ Q10 } & -0.324 & 0.091 \\
\hline & $(0.594)$ & $(0.739)$ \\
\hline \multirow[t]{2}{*}{ Q15 } & -0.869 & -0.138 \\
\hline & $(1.227)$ & $(1.261)$ \\
\hline \multirow[t]{2}{*}{ Q20 } & -1.058 & 0.647 \\
\hline & $(1.570)$ & $(1.647)$ \\
\hline \multirow[t]{2}{*}{ Q25 } & -0.942 & -0.029 \\
\hline & $(2.529)$ & $(2.437)$ \\
\hline \multirow[t]{2}{*}{ Q30 } & -3.791 & 0.565 \\
\hline & $(2.632)$ & $(2.685)$ \\
\hline \multirow[t]{2}{*}{ Q35 } & -2.354 & -0.606 \\
\hline & $(3.523)$ & $(3.603)$ \\
\hline \multirow[t]{2}{*}{ Q40 } & -6.551 & 3.442 \\
\hline & $(4.275)$ & $(4.602)$ \\
\hline \multirow[t]{2}{*}{ Q45 } & $-12.154^{* *}$ & 0.945 \\
\hline & $(5.817)$ & $(5.241)$ \\
\hline \multirow[t]{2}{*}{ Q50 } & $-14.561^{* * *}$ & 1.004 \\
\hline & $(5.450)$ & $(5.190)$ \\
\hline \multirow[t]{2}{*}{ Q55 } & $-17.015^{* * *}$ & 2.687 \\
\hline & $(5.866)$ & $(5.938)$ \\
\hline \multirow[t]{2}{*}{ Q60 } & $-16.877^{* * *}$ & 2.665 \\
\hline & $(6.079)$ & $(6.130)$ \\
\hline \multirow[t]{2}{*}{ Q65 } & $-20.243^{* * *}$ & 1.351 \\
\hline & $(7.745)$ & $(8.072)$ \\
\hline \multirow[t]{2}{*}{ Q70 } & $-28.573^{* * *}$ & 8.878 \\
\hline & $(8.006)$ & $(9.833)$ \\
\hline \multirow[t]{2}{*}{ Q75 } & $-24.879 * * *$ & 10.564 \\
\hline & (9.128) & $(9.417)$ \\
\hline \multirow[t]{2}{*}{ Q80 } & -21.330 & 0.896 \\
\hline & ( 12.985) & $(12.721)$ \\
\hline \multirow[t]{2}{*}{ Q85 } & $-29.018^{*}$ & 1.397 \\
\hline & ( 15.028$)$ & $(15.073)$ \\
\hline \multirow[t]{2}{*}{ Q90 } & -34.287 & 3.816 \\
\hline & $(22.024)$ & $(20.652)$ \\
\hline \multirow[t]{2}{*}{ Q95 } & -63.552 & 12.297 \\
\hline & $(41.254)$ & ( 39.527$)$ \\
\hline
\end{tabular}

Note: Each row of the table presents estimated effects on Internet use for quintile X as QX. Estimated standard errors using bootstrapping are reported in parentheses. ${ }^{*}$ Significant at the 1 percent level. ** Significant at the 5 percent level. * Significant at the 10 percent level. 
Table A7: Event Study of SMS messages by Treatment

\begin{tabular}{|c|c|c|c|c|c|c|c|}
\hline & $\begin{array}{c}(1) \\
\text { Day -3 }\end{array}$ & $\begin{array}{c}(2) \\
\text { Day -2 }\end{array}$ & $\begin{array}{c}(3) \\
\text { Day -1 }\end{array}$ & $\begin{array}{c}(4) \\
\text { Day } 0\end{array}$ & $\begin{array}{c}(5) \\
\text { Day } 1\end{array}$ & $\begin{array}{c}(6) \\
\text { Day } 2\end{array}$ & $\begin{array}{c}(7) \\
\text { Day } 3\end{array}$ \\
\hline \multicolumn{8}{|c|}{ Panel A: Treatment effect } \\
\hline ISP Info & $\begin{array}{c}1.347 \\
(4.753)\end{array}$ & $\begin{array}{c}-0.542 \\
(4.660)\end{array}$ & $\begin{array}{c}0 \\
(0)\end{array}$ & $\begin{array}{c}-6.613 \\
(4.526)\end{array}$ & $\begin{array}{c}-10.660^{* *} \\
(4.529)\end{array}$ & $\begin{array}{c}-4.793 \\
(4.542)\end{array}$ & $\begin{array}{c}-4.885 \\
(4.566)\end{array}$ \\
\hline $\mathrm{PC}$ & $\begin{array}{c}-1.603 \\
(4.759)\end{array}$ & $\begin{array}{c}-0.256 \\
(4.661)\end{array}$ & $\begin{array}{c}0 \\
(0)\end{array}$ & $\begin{array}{c}-1.550 \\
(4.522)\end{array}$ & $\begin{array}{c}-4.419 \\
(4.526)\end{array}$ & $\begin{array}{c}-3.175 \\
(4.539)\end{array}$ & $\begin{array}{c}-3.960 \\
(4.564)\end{array}$ \\
\hline SMS-Only & $\begin{array}{c}2.243 \\
(4.691) \\
\end{array}$ & $\begin{array}{c}1.295 \\
(4.596) \\
\end{array}$ & $\begin{array}{c}0 \\
(0) \\
\end{array}$ & $\begin{array}{c}0.834 \\
(4.463) \\
\end{array}$ & $\begin{array}{c}-5.519 \\
(4.467) \\
\end{array}$ & $\begin{array}{c}1.101 \\
(4.479) \\
\end{array}$ & $\begin{array}{c}-1.135 \\
(4.504) \\
\end{array}$ \\
\hline \multicolumn{8}{|c|}{ Panel B: Above Events } \\
\hline ISP Info & $\begin{array}{c}9.420 \\
(8.134)\end{array}$ & $\begin{array}{c}4.375 \\
(7.979)\end{array}$ & $\begin{array}{c}0 \\
(0)\end{array}$ & $\begin{array}{c}-17.484^{* *} \\
(7.757)\end{array}$ & $\begin{array}{c}-27.921^{* * *} \\
(7.764)\end{array}$ & $\begin{array}{c}-18.247^{* *} \\
(7.783)\end{array}$ & $\begin{array}{c}-21.621^{* * *} \\
(7.823)\end{array}$ \\
\hline $\mathrm{PC}$ & $\begin{array}{c}-2.243 \\
(5.847)\end{array}$ & $\begin{array}{c}-0.889 \\
(5.727)\end{array}$ & $\begin{array}{c}0 \\
(0)\end{array}$ & $\begin{array}{c}-3.002 \\
(5.556)\end{array}$ & $\begin{array}{c}-4.930 \\
(5.561)\end{array}$ & $\begin{array}{c}-4.679 \\
(5.577)\end{array}$ & $\begin{array}{c}-4.502 \\
(5.608)\end{array}$ \\
\hline SMS-Only & $\begin{array}{c}1.457 \\
(5.778) \\
\end{array}$ & $\begin{array}{c}0.178 \\
(5.664) \\
\end{array}$ & $\begin{array}{c}0 \\
(0) \\
\end{array}$ & $\begin{array}{c}-0.148 \\
(5.503)\end{array}$ & $\begin{array}{c}-7.422 \\
(5.507) \\
\end{array}$ & $\begin{array}{c}0.215 \\
(5.522) \\
\end{array}$ & $\begin{array}{c}-2.856 \\
(5.552)\end{array}$ \\
\hline \multicolumn{8}{|c|}{ Panel C: Not-Above Events } \\
\hline ISP Info & $\begin{array}{c}-5.504 \\
(4.929)\end{array}$ & $\begin{array}{c}-5.422 \\
(4.828)\end{array}$ & $\begin{array}{c}0 \\
(0)\end{array}$ & $\begin{array}{c}0.814 \\
(4.687)\end{array}$ & $\begin{array}{c}1.036 \\
(4.691)\end{array}$ & $\begin{array}{c}2.702 \\
(4.705)\end{array}$ & $\begin{array}{c}5.447 \\
(4.731)\end{array}$ \\
\hline $\mathrm{PC}$ & $\begin{array}{c}-0.097 \\
(4.186)\end{array}$ & $\begin{array}{c}1.911 \\
(4.099)\end{array}$ & $\begin{array}{c}0 \\
(0)\end{array}$ & $\begin{array}{c}-0.899 \\
(3.976)\end{array}$ & $\begin{array}{c}-4.638 \\
(3.980)\end{array}$ & $\begin{array}{c}-1.119 \\
(3.991)\end{array}$ & $\begin{array}{c}-3.600 \\
(4.014)\end{array}$ \\
\hline SMS-Only & $\begin{array}{c}0.596 \\
(4.117)\end{array}$ & $\begin{array}{c}-0.852 \\
(4.034)\end{array}$ & $\begin{array}{c}0 \\
(0)\end{array}$ & $\begin{array}{c}0.543 \\
(3.917)\end{array}$ & $\begin{array}{c}-4.954 \\
(3.920)\end{array}$ & $\begin{array}{c}-0.583 \\
(3.931)\end{array}$ & $\begin{array}{c}-1.208 \\
(3.953)\end{array}$ \\
\hline
\end{tabular}

Note: This table presents estimated effects on Internet use measured as MBs downloaded and uploaded for different days around the reception of a SMS. Day 0 marks the day on which the SMSs are received each week. The coefficient for Day -1 is imposed to be 0 for each treatment group. Regressions also include dummies for each event. Robust estimated standard errors are reported in parentheses. ${ }^{* * *}$ Significant at the 1 percent level. ** Significant at the 5 percent level. * Significant at the 10 percent level. 
Table A8: W8 Parental Control Settings Installation, Event Study

\begin{tabular}{lccccccc}
\hline \hline & $(1)$ & $(2)$ & $(3)$ & $(4)$ & $(5)$ & $(6)$ & $(7)$ \\
& Day -3 & Day -2 & Day -1 & Day 0 & Day 1 & Day 2 & Day 3 \\
\hline \multirow{2}{*}{ Panel A : Parental } & Controls & & & & & \\
MB Use & -12.852 & -10.555 & -21.823 & 0 & -21.960 & -15.711 & -1.548 \\
& $(28.384)$ & $(28.375)$ & $(28.367)$ & $(0)$ & $(28.362)$ & $(28.372)$ & $(28.382)$ \\
Panel B: & T2 & & & & & & \\
MB Use & -43.390 & -22.280 & -22.451 & 0 & -14.188 & -0.901 & 25.217 \\
& $(49.181)$ & $(49.166)$ & $(49.153)$ & $(0)$ & $(49.143)$ & $(49.153)$ & $(49.166)$ \\
Panel C: & T3 & & & & & & \\
MB Use & 13.607 & -0.367 & -21.302 & 0 & -28.914 & -29.069 & -25.277 \\
& $(31.493)$ & $(31.483)$ & $(31.474)$ & $(0)$ & $(31.470)$ & $(31.486)$ & $(31.500)$ \\
\hline \hline
\end{tabular}

Notes: This table presents estimated effects on Internet use measured as MBs downloaded and uploaded for different days around the installation of W8 parental control settings.. Day 0 marks the day on which the program was installed. The coefficient for Day 0 is imposed to be 0 for each treatment group. Regressions also include dummies for weeks in which the installation took place. Robust estimated standard errors are reported in parentheses. *** Significant at the 1 percent level. ** Significant at the 5 percent level. * Significant at the 10 percent level. 
Table A9: Event Study for 1st and 2nd Half of Treatment

\begin{tabular}{|c|c|c|c|c|c|c|c|}
\hline & $\begin{array}{c}(1) \\
\text { Day -3 }\end{array}$ & $\begin{array}{c}(2) \\
\text { Day -2 }\end{array}$ & $\begin{array}{c}(3) \\
\text { Day -1 }\end{array}$ & $\begin{array}{c}(4) \\
\text { Day } 0 \\
\end{array}$ & $\begin{array}{c}(5) \\
\text { Day } 1 \\
\end{array}$ & $\begin{array}{c}(6) \\
\text { Day } 2 \\
\end{array}$ & $\begin{array}{c}(7) \\
\text { Day } 3 \\
\end{array}$ \\
\hline \multicolumn{8}{|c|}{ Panel A: 1st Half Period } \\
\hline ISP Info & $\begin{array}{c}-3.677 \\
(6.254)\end{array}$ & $\begin{array}{c}-4.411 \\
(6.135)\end{array}$ & $\begin{array}{c}0 \\
(0)\end{array}$ & $\begin{array}{c}-13.005^{* *} \\
(5.808)\end{array}$ & $\begin{array}{c}-19.689^{* * *} \\
(5.849)\end{array}$ & $\begin{array}{c}-4.398 \\
(5.902)\end{array}$ & $\begin{array}{r}-10.291^{*} \\
(5.939)\end{array}$ \\
\hline $\mathrm{PC}$ & $\begin{array}{c}-7.752 \\
(6.262)\end{array}$ & $\begin{array}{c}-0.765 \\
(6.055)\end{array}$ & $\begin{array}{c}0 \\
(0)\end{array}$ & $\begin{array}{c}-4.521 \\
(5.822)\end{array}$ & $\begin{array}{c}-7.171 \\
(5.863)\end{array}$ & $\begin{array}{c}-4.359 \\
(5.919)\end{array}$ & $\begin{array}{c}-5.746 \\
(5.953)\end{array}$ \\
\hline SMS-Only & $\begin{array}{c}-1.173 \\
(6.186)\end{array}$ & $\begin{array}{c}-1.818 \\
(6.059)\end{array}$ & $\begin{array}{c}0 \\
(0)\end{array}$ & $\begin{array}{c}-0.415 \\
(5.729)\end{array}$ & $\begin{array}{c}-10.337^{*} \\
(5.767)\end{array}$ & $\begin{array}{c}2.670 \\
(5.822)\end{array}$ & $\begin{array}{c}-2.645 \\
(5.860)\end{array}$ \\
\hline \multicolumn{8}{|c|}{ Panel B: 2nd Half Period } \\
\hline ISP Info & $\begin{array}{c}4.832 \\
(7.598)\end{array}$ & $\begin{array}{c}2.515 \\
(7.354)\end{array}$ & $\begin{array}{c}0 \\
(0)\end{array}$ & $\begin{array}{c}-0.461 \\
(7.020)\end{array}$ & $\begin{array}{c}-3.282 \\
(6.983)\end{array}$ & $\begin{array}{c}-8.304 \\
(6.967)\end{array}$ & $\begin{array}{c}-2.453 \\
(7.001)\end{array}$ \\
\hline $\mathrm{PC}$ & $\begin{array}{c}7.169 \\
(7.569)\end{array}$ & $\begin{array}{c}1.322 \\
(7.330)\end{array}$ & $\begin{array}{c}0 \\
(0)\end{array}$ & $\begin{array}{c}0.771 \\
(6.990)\end{array}$ & $\begin{array}{c}-3.606 \\
(6.956)\end{array}$ & $\begin{array}{c}-5.047 \\
(6.939)\end{array}$ & $\begin{array}{c}-5.145 \\
(6.975)\end{array}$ \\
\hline SMS-Only & $\begin{array}{c}6.551 \\
(7.489)\end{array}$ & $\begin{array}{c}6.456 \\
(7.253)\end{array}$ & $\begin{array}{c}0 \\
(0)\end{array}$ & $\begin{array}{c}1.133 \\
(6.929)\end{array}$ & $\begin{array}{c}-2.687 \\
(6.896)\end{array}$ & $\begin{array}{c}-3.744 \\
(6.878)\end{array}$ & $\begin{array}{c}-2.818 \\
(6.911)\end{array}$ \\
\hline
\end{tabular}

Note: This table presents estimated effects on Internet use measured as MBs downloaded and uploaded for different days around the reception of a SMS. Day 0 marks the day on which the SMSs are received each week. The coefficient for Day -1 is imposed to be 0 for each treatment group. Regressions also include dummies for each event. Robust estimated standard errors are reported in parentheses. $* * *$ Significant at the 1 percent level. $* *$ Significant at the 5 percent level. $*$ Significant at the 10 percent level. 
Table A10: Impact of Treatments on Intensity of Internet Use, Pre/Post School

\begin{tabular}{lcc}
\hline \hline & $(1)$ & $(2)$ \\
& Summer & School-in-session \\
\hline Panel A: T1, T2, T3 & \\
$T_{1}$ & -12.992 & $-22.580^{* *}$ \\
& $(12.056)$ & $(9.927)$ \\
$T_{2}$ & 1.017 & -8.536 \\
& $(12.889)$ & $(10.766)$ \\
$T_{3}$ & -12.551 & -10.991 \\
& $(12.220)$ & $(10.532)$ \\
Observations & 7,707 & 7,707 \\
BL Controls & All & X \\
Control Mean & 204.9 & 153.7 \\
\hline & & \\
Panel B: ISP Information and Parental Control \\
ISP Information & -13.280 & $-12.514^{*}$ \\
& $(8.429)$ & $(6.755)$ \\
Parental Controls & 0.729 & 1.527 \\
& $(8.489)$ & $(6.787)$ \\
Observations & 7,707 & 7,707 \\
BL Controls & All & All \\
Control Mean & 204.9 & 153.7 \\
\hline
\end{tabular}

Note: :This table presents estimated effects on Internet use measured as daily average MBs uploaded and downloaded. Column 1 presents estimates for the last two weeks of the vacation period and Column 2 for the first two weeks of the school period. Control variables include the baseline values of mean of MBs of Internet use; guardian gender, age, education level and employment status; number of siblings; and dummies for family composition (indicating whether the child lives with mother, father, step-mother or father's partner, step-father or mother's partner, uncle/aunt, brother/sister, grandfather/grandmother, other relatives, and other non-relatives). Robust estimated standard errors are reported in parentheses. *** Significant at the 1 percent level. ** Significant at the 5 percent level. * Significant at the 10 percent level. 
Table A11: Interactions of Treatments with Random

\begin{tabular}{lcccccc}
\hline \hline & $(1)$ & $(2)$ & $(3)$ & $(4)$ & $(5)$ & $(6)$ \\
Period: & All & All & Week & Week & Weekend & Weekend \\
\hline \multirow{3}{*}{$T_{1}$} & & & & & & \\
& $-18.199^{*}$ & -17.147 & -16.482 & -15.498 & $-22.580^{* *}$ & $-21.357^{*}$ \\
$T_{2}$ & $(11.045)$ & $(11.061)$ & $(11.422)$ & $(11.433)$ & $(11.175)$ & $(11.187)$ \\
& -8.221 & -6.839 & -7.665 & -6.324 & -9.638 & -8.152 \\
$T_{3}$ & $(11.518)$ & $(11.523)$ & $(11.773)$ & $(11.782)$ & $(11.864)$ & $(11.854)$ \\
& $-22.963^{* *}$ & $-21.653^{*}$ & $-22.657^{*}$ & $-21.408^{*}$ & $-23.746^{* *}$ & $-22.279^{*}$ \\
Random & $(11.380)$ & $(11.340)$ & $(11.595)$ & $(11.559)$ & $(11.812)$ & $(11.771)$ \\
& $-23.842^{* *}$ & $-22.497^{* *}$ & $-24.372^{* *}$ & $-22.986^{* *}$ & $-22.488^{*}$ & $-21.250^{*}$ \\
$T_{1}$ x Random & $(11.272)$ & $(11.212)$ & $(11.341)$ & $(11.290)$ & $(12.225)$ & $(12.130)$ \\
& 8.822 & 7.921 & 7.890 & 7.014 & 11.200 & 10.233 \\
$T_{2}$ x Random & $(14.157)$ & $(14.141)$ & $(14.381)$ & $(14.358)$ & $(15.013)$ & $(14.999)$ \\
& 13.664 & 12.572 & 14.962 & 13.836 & 10.351 & 9.348 \\
$T_{3}$ x Random & $(15.103)$ & $(15.057)$ & $(15.193)$ & $(15.154)$ & $(16.234)$ & $(16.165)$ \\
& 21.505 & 19.867 & 20.285 & 18.577 & 24.617 & 23.159 \\
& $(14.287)$ & $(14.205)$ & $(14.318)$ & $(14.249)$ & $(15.676)$ & $(15.565)$ \\
Observations & 7,707 & 7,707 & 7,707 & 7,707 & 7,707 & 7,707 \\
Additional Controls & & $\mathrm{X}$ & & $\mathrm{X}$ & & $\mathrm{X}$ \\
\hline
\end{tabular}

Note: This table presents estimated effects on Internet use measured as daily average MBs uploaded and downloaded. Odd-numbered columns present estimates controlling for MB Use at baseline and even-numbered columns present estimates including all baseline control variables. Control variables include the baseline values of mean of MBs of Internet use; guardian gender, age, education level and employment status; number of siblings; and dummies for family composition (indicating whether the child lives with mother, father, step-mother or father's partner, step-father or mother's partner, uncle/aunt, brother/sister, grandfather/grandmother, other relatives, and other non-relatives). Robust estimated standard errors are reported in parentheses. ${ }^{* * *}$ Significant at the 1 percent level. ** Significant at the 5 percent level. * Significant at the 10 percent level. 